\title{
METEOROLOGY, AIR QUALITY, AND HEALTH IN LONDON The Clearflo Project
}

by S. I. Bohnenstengel, S. E. Belcher, A. Aiken, J. D. Allan, G. Allen, A. Bacak, T. J. Bannan, J. F. Barlow, D. C. S. Beddows, W. J. Bloss, A. M. Booth, C. Chemel, O. Coceal, C. F. Di Marco, M. K. Dubey, K. H. Faloon, Z. L. Fleming, M. Furger, J. K. Gietl, R. R. Graves, D. C. Green, C. S. B. Grimmond, C. H. Halios, J. F. Hamilton, R. M. Harrison, M. R. Heal, D. E. Heard, C. Helfter, S. C. Herndon, R. E. Holmes, J. R. Hopkins, A. M. Jones, F. J. Kelly, S. Kotthaus, B. Langford, J. D. Lee, R. J. Leigh, A. C. Lewis, R. T. Lidster, F. D. Lopez-Hilfiker, J. B. McQuaid, C. Mohr, P. S. Monks, E. Nemitz, N. L. Ng, C. J. Percival, A. S. H. Prévôt, H. M. A. Ricketts, R. Sokhi, D. Stone, J. A. Thornton, A. H. Tremper, A. C. Valach, S. Visser, L. K. Whalley, L. R. Williams, L. Xu, D. E. Young, and P. Zotter

The Clean Air for London (ClearfLo) project provides integrated measurements

of the meteorology, composition, and particulate loading of the urban atmosphere in London, United Kingdom, to improve predictive capability for air quality.

T he sharply increasing urban population in 2007 exceeded the rural population on a global basis (UN Department of Economic and Social Affairs 2013). Urban populations are exposed to stressful environmental conditions, such as local and nonlocal pollutants, that cause poor air quality and microclimates that exacerbate heat stress during heat waves. These are projected to increase in a warming climate. Our cities are therefore nexus points for several environmental health stresses that we currently face (Rydin et al. 2012) and the interacting issues around sustainability and human health.

The purpose of this paper is to introduce the Clean Air for London (ClearfLo) project, which investigates the atmospheric science that underpins these health stresses, with a particular focus on the urban increment in atmospheric drivers. We focused on three atmospheric drivers of environmental health stress in cities, namely, heat, gas-phase pollutants, and particulate matter (PM).
Health stresses from the urban atmospheric environment. Heat waves have an impact on human health. Populations typically display an optimal temperature range at which the (daily or weekly) mortality rate is lowest. Mortality rates rise as temperatures exceed this optimal range (e.g., Rydin et al. 2012). The 2003 European heat wave (Stedman 2004) in combination with air pollution was responsible for more than 2000 excess deaths in the United Kingdom (Johnson et al. 2005). Under a warming climate, the risks posed by heat stress are predicted to increase (Hacker et al. 2005). People living in urban environments are exposed to higher temperatures than in nonurban regions. Thus, heat-related deaths could be higher within urban areas (Mavrogianni et al. 2011). Hence, ClearfLo is concerned with measuring the factors controlling the urban atmospheric boundary layer, that is, the surface energy balance.

The World Health Organization (WHO) reported (WHO 2006) that the strongest effects of air quality 
on health are attributable to $\mathrm{PM}$, followed by ozone $\left(\mathrm{O}_{3}\right)$ and nitrogen dioxide $\left(\mathrm{NO}_{2}\right)$. A recent report (Guerreiro et al. 2013) indicates that in 2011 up to $88 \%$ of the urban population in Europe was exposed to concentrations exceeding the WHO air quality guidelines for $\mathrm{PM}_{10}$ (defined as particles that pass through a size-selective inlet with a $50 \%$ efficiency cutoff at $10-\mu \mathrm{m}$ aerodynamic diameter, representative of the inhalable fraction). It is estimated that a reduction of $\mathrm{PM}_{10}$ to the WHO annual-mean guideline of $20 \mu \mathrm{g} \mathrm{m}^{-3}$ would reduce attributable deaths per year in Europe by 22,000 . Further, this would lead to a substantial improvement in the quality of life for millions with a preexisting respiratory or cardiovascular disease (COMEAP 2010).

Epidemiological studies consistently demonstrate an association between the PM mass concentration and reduced cardiorespiratory health (e.g., Brunekreef and Holgate 2002; Shah et al. 2013). However, the estimated magnitude of the health impacts per incremental increase in $\mathrm{PM}_{10}$ or $\mathrm{PM}_{2.5}$ mass varies between studies (e.g., Bell et al. 2004;
Janssen et al. 2002). Variability and differences across study populations might explain some of the results, but the differing chemical composition and size distribution of particles from the various study sites may also play a role. PM mass concentration does not account for the widely varying sources, composition, and size distribution of the PM loading, which may lead to differences in biological activity of the particles within the human body. The $\mathrm{PM}_{10}$ concentration measured in London, United Kingdom, is composed of particles from diverse sources, including vehicle exhaust and nonexhaust emissions, solid fuel combustion, marine aerosol, and inorganic and organic secondary aerosol. Research to date has yet to clearly define the differential toxicity of particles from different sources. Strategies to reduce PM concentrations in urban areas require knowledge of the contribution of the different sources. Similarly, studies of health impacts will be greatly strengthened by a fuller understanding of the chemical and physical properties of particulate matter exposures. ClearfLo is responding to this need by measuring the full size
AfFiliations: Bohnenstengel, Belcher, Barlow, Grimmond, HaLIOS, and KotTHAUS—Department of Meteorology, University of Reading, Reading, United Kingdom; AIKEN AND DUBEY — Earth System Observations, Los Alamos National Laboratory, Los Alamos, New Mexico; Allan-National Centre for Atmospheric Science, and School of Earth,Atmospheric and Environmental Science, University of Manchester, Manchester, United Kingdom; AlLEN, BACAK, BANNAN, BOOTH, PERCIVAL, RICKETTS, AND YOUNG - School of Earth, Atmospheric and Environmental Science, University of Manchester, Manchester, United Kingdom; Beddows, Bloss, Faloon, GieTL, AND Jones-School of Geography, Earth and Environmental Sciences, University of Birmingham, Birmingham, United Kingdom; CHEMEL-National Centre for Atmospheric Science, University of Hertfordshire, Hatfield, United Kingdom; COCEAL—National Centre for Atmospheric Science, Department of Meteorology, University of Reading, Reading, United Kingdom; Di Marco, Helfter, Langford, and Nemitz-Centre for Ecology and Hydrology, Penicuik, United Kingdom; FLEMING - Department of Chemistry, and National Centre for Atmospheric Science, University of Leicester, Leicester, United Kingdom; FURGER, PrÉVÔt, VISSER, AND ZOTTER - Laboratory of Atmospheric Chemistry, Paul Scherrer Institute, Villigen, Switzerland; GRAVES AND LEIGH—Department of Physics and Astronomy, University of Leicester, Leicester, United Kingdom; GreEN AND TREMPER — School of Biomedical Sciences, King's College London, London, United Kingdom; HAMILTON, HOLMES, AND LIDSTER—Department of Chemistry, University of York, York, United Kingdom; HARRISONDepartment of Environmental Sciences, and Center of Excellence in Environmental Studies, King Abdulaziz University, Jeddah, Saudi Arabia, and Division of Environmental Health and Risk Management, and School of Geography, Earth and Environmental Sciences, University of Birmingham, Birmingham, United Kingdom; HEAL-School of Chemistry, University of Edinburgh, Edinburgh, United Kingdom; HEARD, STONE, AND WHALLEY - School of Chemistry, University of Leeds, Leeds, United
Kingdom; HeRnDON-Center for Atmospheric and Environmental Chemistry, Aerodyne Research, Inc., Billerica, Massachusetts; HopKINS AND LeWIS - National Centre for Atmospheric Science, University of York, York, United Kingdom; KelLY-Medical Research CouncilPublic Health England Centre for Environment and Health, and King's College London, London, United Kingdom; LEE-National Centre for Atmospheric Science, and Department of Chemistry, University of York, York, United Kingdom; LOPEZ-HILFIKER, MOHR, AND THORNTONDepartment of Atmospheric Sciences, University of Washington, Seattle, Washington; McQUAID—School of Earth and Environment, University of Leeds, Leeds, United Kingdom; MonKs—Department of Chemistry, University of Leicester, Leicester, United Kingdom; NG-School of Chemical and Biomolecular Engineering, and School of Earth and Atmospheric Sciences, Georgia Institute of Technology, Atlanta, Georgia; SOKH—Centre for Atmospheric and Instrumentation Research, University of Hertfordshire, Hatfield, United Kingdom;

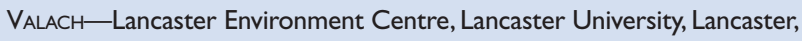
United Kingdom; WILLIAMS-Center for Aerosol and Cloud Chemistry, Aerodyne Research, Inc., Billerica, Massachusetts; Xu—School of Chemical and Biomolecular Engineering, Georgia Institute of Technology, Atlanta, Georgia

CORRESPONDING AUTHOR: Sylvia I. Bohnenstengel, Department of Meteorology, University of Reading, Earley Gate, P.O. Box 243, Reading RG6 6BB, United Kingdom

E-mail: s.i.l.d.bohnenstengel@reading.ac.uk

The abstract for this article can be found in this issue, following the table of contents.

DOI:10.1175/BAMS-D-12-00245.I

A supplement to this article is available online (I0.II75/BAMS-D-12-00245.2)

In final form 9 July 2014

(C)2015 American Meteorological Society 
spectrum and composition of PM. Data generated in this way may also shed light on topical phenomena such as why $\mathrm{PM}_{10}$ concentrations have remained largely unchanged in recent years, despite implementation of extensive abatement measures and consequent reduction of primary emissions and of precursors to secondary pollutants (Harrison et al. 2012).

In addition to PM, oxidant gases such as $\mathrm{O}_{3}$ and $\mathrm{NO}_{2}$ are also associated with detrimental effects on public health. Owing to high correlations between $\mathrm{NO}_{2}$ and other pollutants, independent effects are difficult to identify. Nevertheless, there is evidence that short-term exposure to $\mathrm{NO}_{2}$ causes inflammation and increased airway hyperresponsiveness, while longterm studies suggest associations with cardiorespiratory mortality and children's respiratory symptoms (WHO 2006, 2013). Mortality and cardiorespiratory hospital admissions have been reported following short-term exposure to $\mathrm{O}_{3}$, and a significant increase in the risk of death from respiratory causes has been reported following long-term exposure (Jerrett et al. 2009). Levels of $\mathrm{O}_{3}$ and $\mathrm{NO}_{2}$ also play a large role in oxidation chemistry in urban areas, which is complex and not entirely understood. Furthermore, pollutants such as black carbon (BC) and $\mathrm{O}_{3}$ act as climate forcing agents; concentrations of these are expected to increase, and the control of air quality pollutants might aid attainment of short-term climate change targets (von Schneidemesser and Monks 2013; Bond et al. 2013). Hence, ClearfLo is focusing on measuring a wide range of chemical species important to chemical processing of $\mathrm{O}_{3}$ and $\mathrm{NO}_{2}$.

The challenges posed to atmospheric science. Efforts within the research community to understand the local meteorology and air quality of urban areas have increased considerably over recent years. This increased interest was reflected by the theme of the 89th American Meteorological Society conference in 2009, which was "Urban weather and climate: Now and the future," and the American Meteorological Society annual meeting 2014 theme, which was "Extreme weather-Climate and the built environment: New perspectives, opportunities, and tools." Further, there have been a number of large campaigns measuring urban meteorology and air quality, for example, in Marseille in France (Cros et al. 2004); Basel in Switzerland (Rotach et al. 2005); Oklahoma City, Oklahoma, in the United States (Allwine et al. 2004; Allwine and Flaherty 2006); Toulouse in France (Masson et al. 2008); and Montreal and Vancouver in Canada (www.epicc .ca). These are complemented with developments of physically based parameterizations of the urban surface energy balance (e.g., Grimmond et al. 2010) of local meteorology (e.g., Bohnenstengel et al. 2011) and of atmospheric dispersion (e.g., Belcher 2005).

ClearfLo addresses the atmospheric drivers of health stresses due to exposure to poor air quality (AQ) through a program of integrated measurements in London and modeling. In London, one of Europe's largest and most congested cities, air quality is an area of continued public and policy interest. Despite progress over the past 50 years in improving air quality, London still breaches the European air quality limit values for certain pollutants, notably $\mathrm{NO}_{2}$ and PM. Hence, air pollution remains a serious health risk (Carslaw et al. 2011; see also www.londonair .org.uk/LondonAir/Default.aspx). ClearfLo builds upon recent modeling and monitoring experience in London: for local meteorology (Bohnenstengel et al. 2011, 2013; Loridan et al. 2013), atmospheric dispersion (Arnold et al. 2004; Wood et al. 2009), atmospheric composition (Harrison et al. 2012), the influence of synoptic-scale meteorological conditions (Pope et al. 2014), and health and comfort impacts on indoor environments (Hacker et al. 2005; Mavrogianni et al. 2011).

ClearfLo has six overarching scientific aims:

- To establish an infrastructure to measure meteorology, gas-phase composition, and particulate loading of London's atmosphere using state-of-the art instruments at both street-level and elevated sites

- To develop long-term measurements of London's atmosphere in order to determine the relationships between surface meteorology, gas-phase composition, and PM at a rural location, a city background site (away from local traffic sources), and a city street site (close to local traffic sources) through the full range of seasonal cycles

- To determine the meteorological processes that control the heat content, mixing properties, and depth of London's urban boundary layer and place it into the context of the rural surroundings

- To determine the chemical processes that control the loading of $\mathrm{O}_{3}$ and $\mathrm{NO}_{2}$ in London's atmosphere, particularly the role of biogenic emissions, and place the urban concentrations into the synoptic context

- To determine the chemical and physical processes that control the size and number distribution of $\mathrm{PM}$ in London's atmosphere and identify their chemical sources, and place the urban characteristics into the synoptic context 
- To evaluate the strengths and weaknesses of a current air quality model

The purpose of this paper is to introduce ClearfLo by elaborating on these scientific aims and to describe the measurements made together with examples of some of the results from analysis of the ClearfLo data.

\section{THE CLEARFLO MEASUREMENT} CAMPAIGNS. The long-term measurements from January 2011 through October 2013 (Table ES1) provided a major focus for ClearfLo. First, ClearfLo aims to quantify the urban increment in atmospheric conditions, gas-phase pollutant, and particulate concentrations. Hence, measurements were made both within the city and at two rural locations. Second, and an important innovation over previous large collaborative campaigns, was to make long-term measurements to observe the seasonal variation in the drivers of the meteorology, gas-phase chemistry, and particulate loading of London's atmosphere. These long-term measurements then provide a context for more detailed short-term measurements, during two intensive observation periods (IOPs). Third, we aimed to make measurements at both the surface $(2-5 \mathrm{~m}$ above ground level) and at elevated locations. Many routine air quality measurements are made within a few meters of ground level, while air quality models usually estimate the near-surface concentrations of pollutants from their first grid point, which is assumed to lie within a parameterized surface layer over an idealized rough surface. Hence, we aimed to investigate the contrasts between measurements made near the surface and at elevated locations, and the impact of this methodological discrepancy.

Greater London lies within the M25 motorway, which has a diameter of about $50 \mathrm{~km}$. It is located in the Thames Valley, in the southeastern United Kingdom, with slightly higher orography toward the north and south. The River Thames divides London into northern and southern parts (Fig. 1). The many parks provide considerable green space in London. Tall buildings are concentrated around Canary Wharf and in the city of London adjacent to the Thames, while low-rise constructions (fewer than about five stories) dominate the remaining areas, where there are only few tall structures (e.g., BT Tower in west-central London).

New infrastructure established for the long-term measurements was sited at existing air quality monitoring stations, nearby and on BT Tower (Fig. 1). The extensive London Air Quality Network (LAQN; www.londonair.org.uk/LondonAir/Default.aspx) makes routine measurements of $\mathrm{PM}_{10}$, the main gasphase pollutants ( $\mathrm{NO}, \mathrm{NO}_{2}, \mathrm{O}_{3}$, and $\mathrm{CO}$ ), and basic meteorological variables (temperature, wind, pressure, and humidity). Two LAQN sites were upgraded for the surface measurements (Fig. 1): Marylebone Road (MR), a curbside site close to a very busy road; and Sion-Manning RC Girls' School in North Kensington (NK), an urban background site (Bigi and Harrison 2010) in a residential area away from very busy roads. The most elevated site was on the BT Tower, $190 \mathrm{~m}$ above ground level, near Marylebone Road. All the BT Tower flux measurements were conducted at $190 \mathrm{~m}$ and the particulate measurements at $162 \mathrm{~m}$. Other elevated sites include Westminster City Council (WCC) on Marylebone Road with instruments [see Tables ES1-ES3 (http://dx.doi.org// 0.1175 /BAMS-D-I2-00245.2) for complete acronym expansions] located on the building at $18 \mathrm{~m}$ above ground level, the King's College Strand Campus (KSS) with $59 \mathrm{~m}$ above ground level (and lower), and three tall buildings in Kensington (NTT, NDT, NGT). Together these sites provide extensive coverage, with a number of locations at ground level within the city and at a range of heights above ground level. The in situ observations were further complemented by remote sensing equipment to cover wider horizontal and vertical scales.

Rural sites enhanced existing infrastructure near London (Fig. 1): to the west of London at Harwell \{one of the two U.K. cooperative programs for monitoring and evaluating of the long-range transmission of air pollutants in Europe [European Monitoring and Evaluation Programme (EMEP)]\}; to the southwest of London at Chilbolton, where extensive remote sensing instrumentation (e.g., meteorological radars and lidars) are located to characterize the rural boundary layer (Illingworth et al. 2007; Barrett et al. 2009; Hogan et al. 2009); and to the southeast of London at Detling, where an air quality site was upgraded significantly.

The same core instruments (see Table ES1) were deployed at each of the long-term sites. The spread of sites allows us to determine the traffic-controlled increment in pollutants and to compare it against emission databases used as input to air quality models. Remote sensing instruments at each site enabled determination of the mixing height, which help to interpret the air quality measurements, as concentrations depend on the depth of the urban atmospheric boundary layer. Fast-response $\mathrm{NO}_{x}$, $\mathrm{NO}_{y}, \mathrm{CO}$, and $\mathrm{O}_{3}$ instruments were deployed in conjunction with an eddy covariance system on the BT Tower to measure fluxes of pollutants and energy 
over a large footprint. Eddy covariance observations at KCL Strand provided turbulent fluxes of energy and $\mathrm{CO}_{2}$ over a smaller footprint. Scintillometers deployed across the Royal Borough of Kensington and Chelsea measured energy exchanges over a large footprint. Comparison of these measurements allows an assessment of the heterogeneity of the fluxes. The long-term measurements are then used to explore the seasonal variation of the urban boundary layer meteorology and composition.

During the winter IOP (6 January-11 February 2012) and summer IOP (21 July-23 August 2012, which includes the 2012 London Olympics), the meteorology, gas-phase chemistry, and PM loading were observed in more detail (instruments and locations

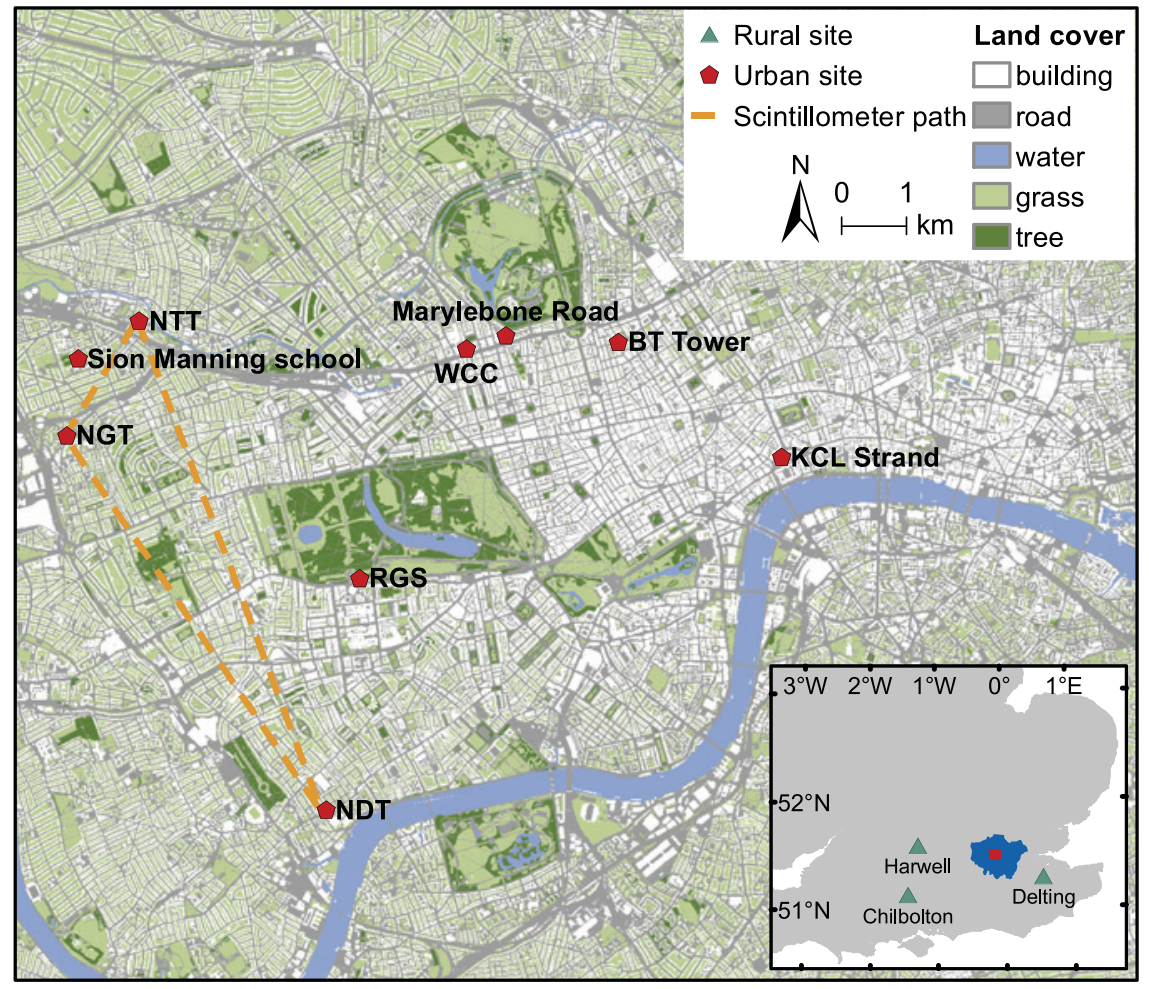

Fig. I. Inset: Measurements were undertaken in London (blue shaded area) and at three rural sites (green triangles). The urban observations were conducted at several locations in central London (red in inset and main map) north of the River Thames (blue, main map). For reference, Hyde Park is the green area directly north of the Royal Geographical Society (RGS; with the Institute of British Geographers) site. Tables ESI-ES3 give details of instrumentation and sites. are listed in Tables ES2 and

ES3). The main objectives of the IOPs were as follows:

1) To establish the vertical structure of London's urban boundary layer, its spatial variability due to changes in land-cover type, and its diurnal evolution, including downward mixing of regional air as a pollutant source. Remote sensing devices were used to address this objective, including several Doppler lidars and scintillometers for the meteorology and the CityScan instrument for $\mathrm{NO}_{2}$ (see "CityScan" for more information).

2) To measure a range of gas-phase species to enable closure of the oxidation budget of London's atmosphere. For example, we measured a range of radical species, particularly $\mathrm{OH}, \mathrm{HO}_{2}, \mathrm{RO}_{2}$, together with their sources and sinks. In addition we made measurements to quantify the relative roles of anthropogenic and biogenic organic species present in an urban background environment. A range of chemical analyzers were deployed, including a dual-channel gas chromatograph to measure speciated $\mathrm{C}_{2}-\mathrm{C}_{7}$ volatile organic

compounds and a comprehensive two-dimensional gas chromatography with flame ionization detector (GCxGC-FID) system for $\mathrm{C}_{5}-\mathrm{C}_{14}$, and a protontransfer-reaction mass spectrometer (PTR-MS).

3) To assess the physical and compositional properties of $\mathrm{PM}$, a range of measurements was made to determine its size distribution and chemical composition, including elemental and black carbon, organic aerosol, and elemental and ionic content. These measurements will help determine the various sources of PM.

Much of the instrumentation for the IOPs was located at Sion Manning School in North Kensington near the NK long-term measurement site. During the winter IOP, a large U.S. team supported by the Department of Energy (DOE) and a team from Switzerland provided substantial additional meteorological variables and gas- and aerosol-phase measurements at the Detling rural site. These additional data allow for a detailed characterization of atmospheric concentrations, chemical aging, and meteorological processes in 
the rural surroundings and hence a more detailed investigation of the urban increment.

\section{FIRST RESULTS FROM THE CLEARFLO MEASUREMENTS. During the ClearfLo cam-} paign, $\mathrm{O}_{3}$ concentrations breached the European Union (EU) limit value $\left(100 \mu \mathrm{g} \mathrm{m}^{-3}\right.$ as an 8 -h mean, not to be exceeded more than 10 times per year) at the NK site on 21 days in 2011 and 14 days in 2012 (none during the winter IOP), of which 7 days were during the summer IOP. The $\mathrm{NO}_{2}$ limit $\left(200 \mu \mathrm{g} \mathrm{m}^{-3}\right.$ as a 1-h mean, not to be exceeded more than 18 times per year) was exceeded on one occasion during 2012 during the winter IOP, and the $\mathrm{PM}_{10}$ limit $\left(50 \mu \mathrm{g} \mathrm{m}^{-3}\right.$ as a 24 -h mean, not to be exceeded more than 35 times per year) was exceeded on 15 days in 2011 and 7 days in 2012, of which 2 days coincided with the winter IOP. Carbon monoxide $\left(10 \mathrm{mg} \mathrm{m}^{-3}\right.$ as a maximum daily running-8-h mean) breached EU limits on no occasion during the campaign at NK.

London's air quality is determined by a combination of pollutants advected in from beyond the urban catchment and those emitted locally (Singh et al. 2013), together with their chemical processing and meteorological processes. To determine the origin of air arriving at London during the IOPs, the Met Office's Numerical
Atmospheric-Dispersion Modelling Environment (NAME) model (Jones et al. 2007) is used to track the arrival pathways of air to the ClearfLo sites. A weekly summary of the meteorological conditions during the IOPs is available online (www.clearflo .ac.uk). The NAME model uses Met Office Unified Model reanalysis meteorological data $(25-\mathrm{km}$ resolution) to simulate the backward movement of tracer particles according to atmospheric conditions and turbulence. For this study, 10,000 theoretical air particles are released at the measurement point of interest (here, $25 \mathrm{~m}$ above ground level). The first three vertical levels in NAME are 20,50, and $100 \mathrm{~m}$ above ground level and as there is no urban canopy model (i.e., no buildings), this height is chosen to simulate the flow for a site. These particles are followed as they spread backward in time (for when they remain in the $0-100-\mathrm{m}$ surface layer), showing the probable pathways the air passed over at surface level, which would influence the emissions. Trajectories are calculated for two time scales (the preceding 10 days and $24 \mathrm{~h}$ ).

Figure 2 shows the probable source locations and pathways for the 24-h back trajectories calculated for each 3-h period of the IOPs, and highlights changes in wind direction and areas of influence. Changes in chemical composition can thus be correlated with

\section{CITYSCAN}

CityScan is a Hemispherical Scanning Imaging Differential Optical Absorption Spectrometer (HSI-DOAS) instrument that was installed in multiple locations within London during both the summer and winter ClearfLo IOPs. More information regarding the instrument design can be found in R. J. Leigh et al. (2014, unpublished manuscript). Briefly, it consists of an imaging spectrometer, operating in the visible wavelength region, mounted inside a rotating weatherproof housing. The field of view that results from the imaging optics and rotation of the instruments is extensive, ranging from the zenith to $-5^{\circ}$ below the horizon vertically with 128 vertically resolved elements measured concurrently. The instrument rotates in a full $360^{\circ}$ azimuthally at a rate of $1^{\circ} \mathrm{s}^{-1}$, providing a full hemisphere of data every $6 \mathrm{~min}$.

Scattered sunlight spectra collected by CityScan are analyzed using the DOAS method, described in Platt and Stutz (2008), to produce differential slant column densities (DSCDs) for nitrogen dioxide $\left(\mathrm{NO}_{2}\right)$ and the oxygen dimer $\left(\mathrm{O}_{4}\right)$. These DSCDs are a measure of the concentration of the trace gas of interest over an integrated line of sight. During the winter IOP, two instruments were installed on rooftops in North Kensington and Chelsea with a third instrument installed in Soho (installation shown in Fig. SBI) for the summer IOP.
Data collected by these instruments can be used to visualize the spatial variability of $\mathrm{NO}_{2}$ and $\mathrm{O}_{4}$ within an urban environment with unprecedented spatial and temporal resolution. Data from two or more instruments will be analyzed using tomographic methods to establish 3D gas plumes.

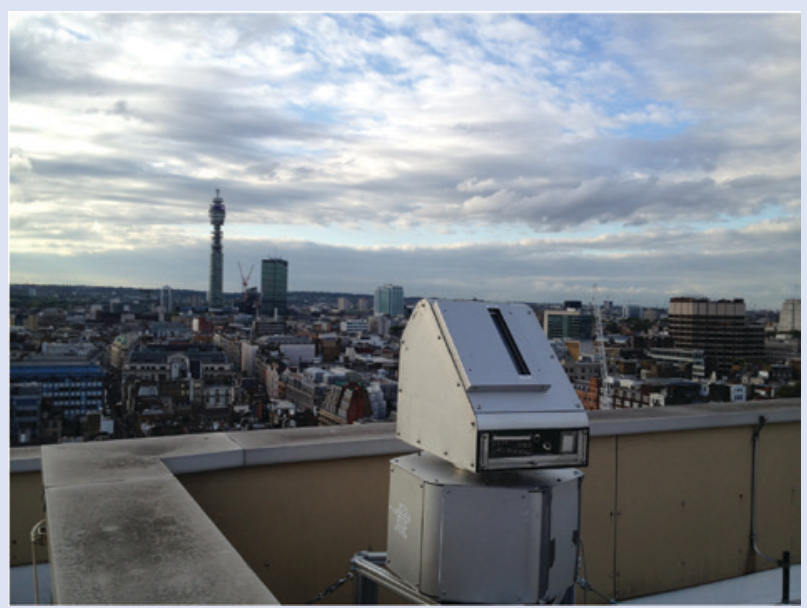

FIG. SBI. Deployment of one of the three CityScan instruments installed during the summer IOP in London. 
changes in the airmass regional influence. On most days London experiences a mix of local sources and remotely advected pollution, as might be expected.

Urban increment in boundary layer meteorology. The boundary layer undergoes a strong diurnal cycle that leads to variations in dilution, mixing, and entrainment of pollutants. As the daytime boundary layer grows by convective heating, it dilutes concentrations by mixing pollutants over a deeper volume. However, as it deepens, the boundary layer also entrains air from above, which has the composition of upwind air. Nighttime surface inversions are likely to trap pollutants in a shallow boundary layer near the surface. During these conditions entrainment from above the boundary layer is also small. Hence, the boundary layer evolution plays an important role in controlling the composition, and so it is important to contrast the rural and urban boundary layer evolutions.

The surface energy balance drives the evolution of the boundary layer. The diurnal cycle of the surface energy balance of urban areas has been extensively studied in the past 10 years. Urban areas have a large thermal inertia that allows them to store more energy during the day than rural areas (Grimmond and Oke 1999; Bohnenstengel et al. 2011). This excess energy is released back into the atmosphere at night by maintaining a positive sensible heat flux (e.g., Bohnenstengel et al. 2013; Kotthaus and Grimmond 2014a). More generally, the lower cooling in the urban area generates the wellknown urban heat island

a) (e.g., Harman and Belcher 2006; Bohnenstengel et al. 2011; Chemel and Sokhi 2012). Bohnenstengel et al. (2013) have shown that anthropogenic heat fluxes can tip the balance between a stable and an unstable stratification of the urban boundary layer at night in winter. These processes mean that the nocturnal urban boundary layer can remain convectively forced and hence deeper and well mixed even long after sunset, when the rural boundary becomes stable (Hunt et al. 2013).

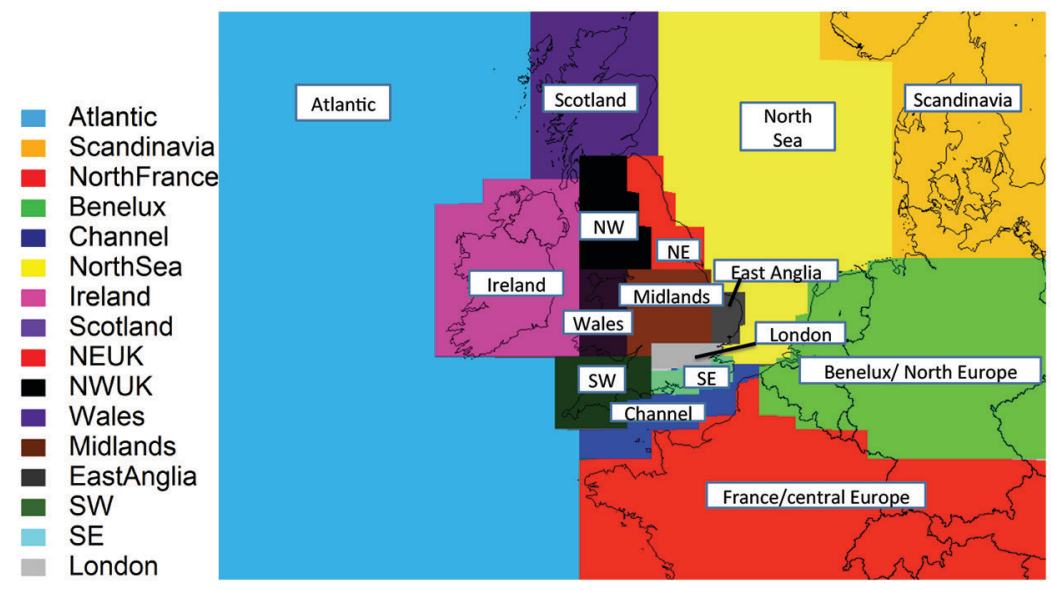

b) 1007 WINTER

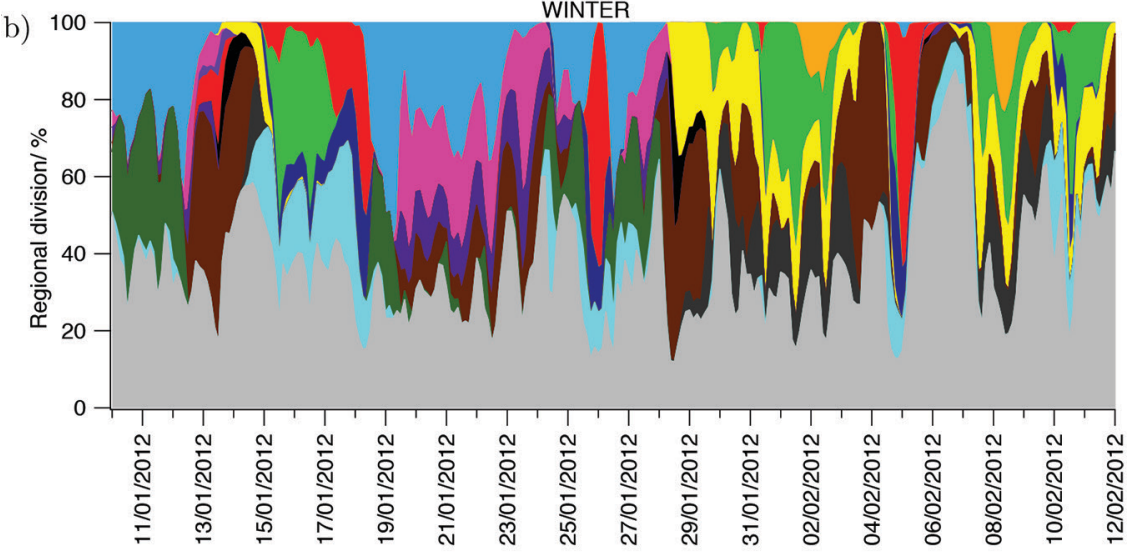

c) $100-$ SUMMER

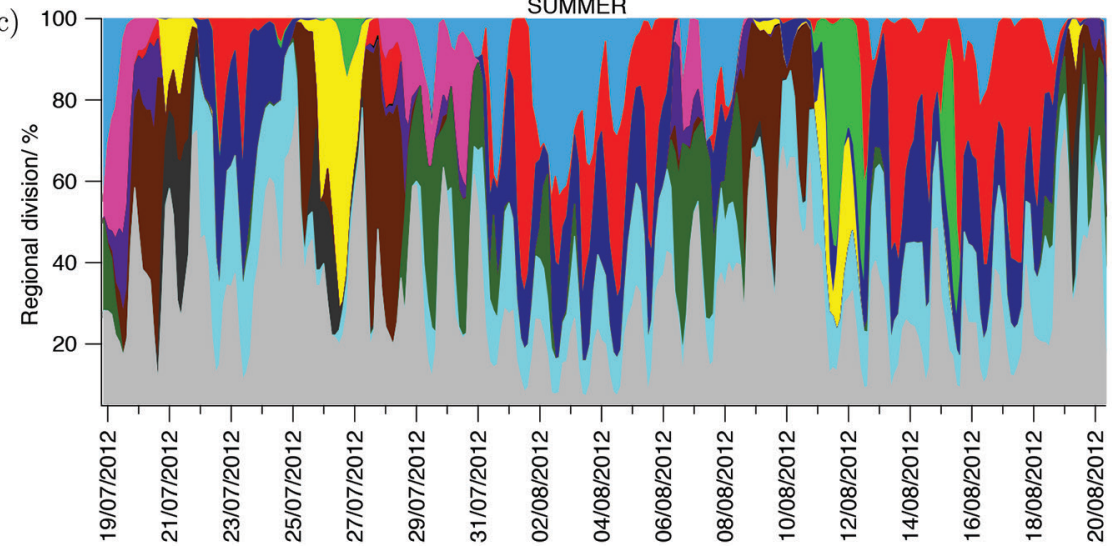

FIG. 2. (a) Regions for the origin of air masses, and percentage time spent over each region by air masses arriving in London, computed using the NAME model, during (b) winter IOP and (c) summer IOP. 
With ClearfLo's focus on air quality, the boundary layer mixing height was an important variable to measure. Mixing heights (MHs) were measured in central London and rural Chilbolton using three
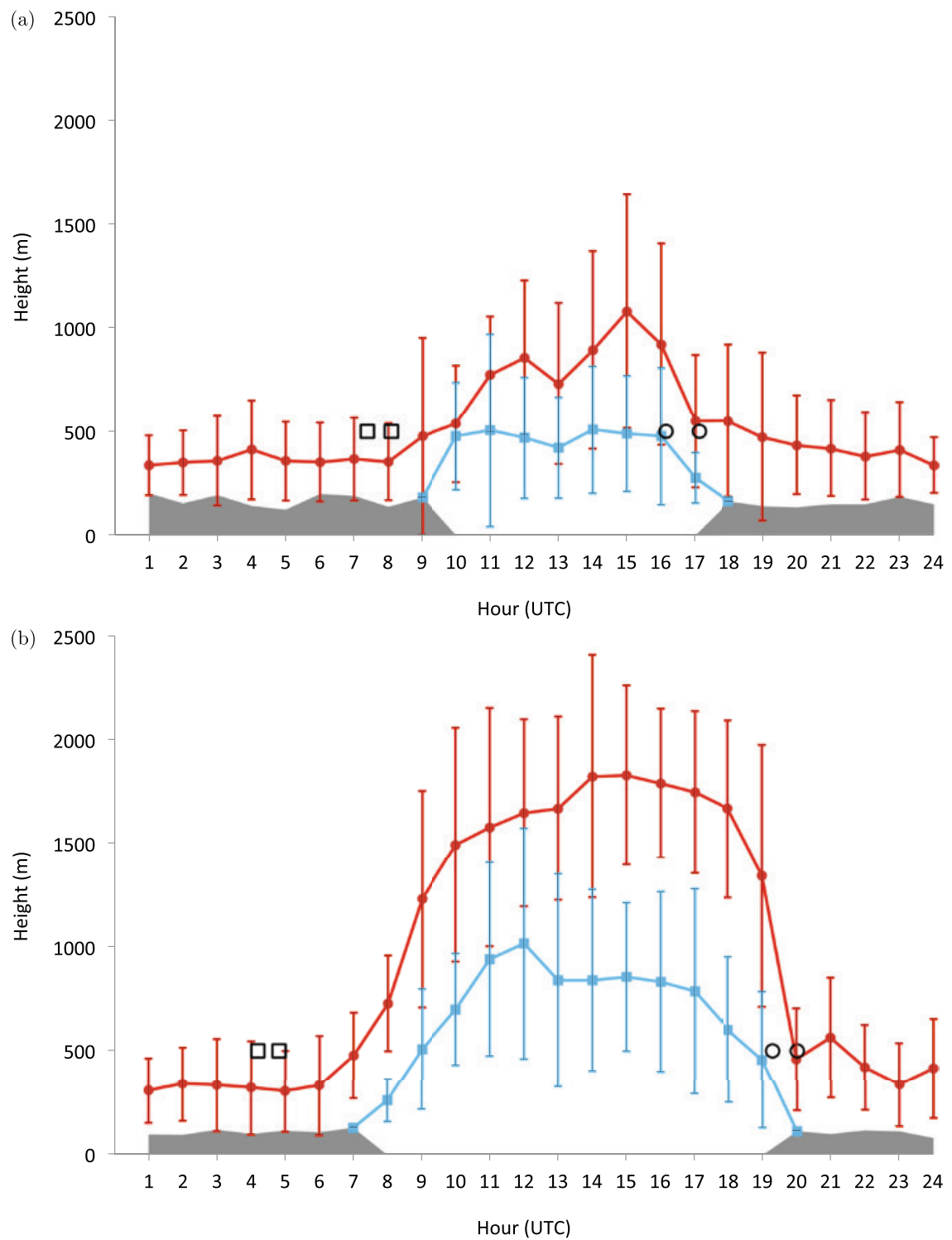

FIG. 3. MHs derived from lidar turbulence for central London (red line) and Chilbolton (blue line) and standard deviations (bars) for (a) winter IOP and (b) summer IOP. The London MHs are derived from lidars located on the rooftop of Westminster Council House (6-II Jan 20I2), at Imperial College (II Jan-II Feb 20I2), and at North Kensington (23 Jul-I7 Aug 20I2). The Chilbolton data analyzed are for the periods 6 Jan-II Feb and 2I Jul-23 Aug 2012. To account for the Doppler lidar's limited sampling rate, a spectral correction is applied (Barlow et al. 2015; Hogan et al. 2009); a range of threshold values of vertical velocity variance from 0.080 to $0.121 \mathrm{~m}^{2} \mathrm{~s}^{-2}$ are considered. Hours with more than $60 \%$ (within the IOP period) are used to determine the mean and standard deviation. For the hours with less than $60 \%$ data availability, the $\mathrm{MH}$ is set to $80 \mathrm{~m}$ (half the height of the lidar gate). This only affects nighttime values (1800-0900 UTC in winter and 2000-0700 UTC in summer), and these periods are shaded gray (no standard deviation). Ranges of sunrise (open squares) and sunset (open circles) times are shown. where the vertical velocity variance drops below a threshold value (Barlow et al. 2011).

MHs based on a turbulence threshold are higher in London than at Chilbolton during both daytime and nighttime. During the night, the $\mathrm{MH}$ is maintained at just below $400 \mathrm{~m}$ over the urban area, while the estimates are more uncertain for the rural surroundings because it only reaches heights below the lowest lidar measurement level. MHs are deeper in summer, when there is more radiative forcing than in winter due to enhanced convective forcing from surface sensible heat fluxes, which are shown in Fig. 4. Daytime MHs in winter are fairly constant over Chilbolton, while over London they grow until the late afternoon.

Presumably the deeper $\mathrm{MH}$ over London is driven by the higher surface roughness of the urban surface and the larger turbulent sensible heat flux $Q_{H}$, the latter partly enhanced by anthropogenic heat. Measurement of $Q_{H}$ was performed using eddy covariance (EC) and large aperture scintillometry (LAS) at different sites in central London (see Table ES1; Fig. 1). Because of the different measurement heights, the towerbased EC observations are influenced by processes at different scales (BT Tower: 

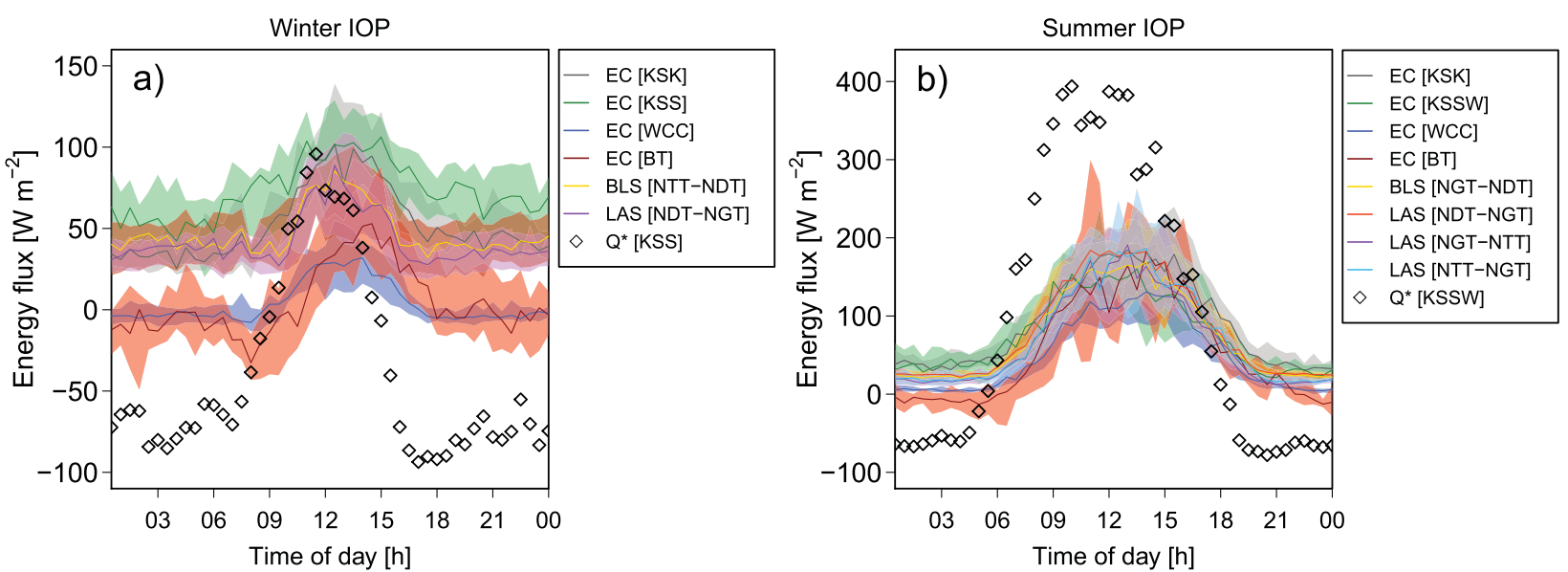

FIG. 4. Median diurnal cycle of 30-min-averaged $Q H$ for the (a) winter IOP and (b) summer IOP derived from EC (at KSK, KSS, KSSW, WCC, and BT Tower) and LAS (paths between NDT, NGT, and NTT) with interquartile range (shading) and median diurnal $Q^{*}$ (diamonds). Scales differ between (a) and (b). Statistics calculated based on times with data available at all sites only. Abbreviations for sites are listed in Tables ES I-ES3.The EC fluxes at KSK, KSS, and KSSW (Table ES I ; Fig. I) are calculated according to Kotthaus and Grimmond (20 I 2, 20 I 4a); at BT Tower and WCC they are calculated according to Wood et al. (20 I 0); and fluxes from scintillometry are calculated according to Mustchin et al. (2013).

local to city scale; KSS and KSSW: local scale; KSK and WCC: local to microscale). The LAS measurements integrate over a larger surface source area $\left(>1 \mathrm{~km}^{2}\right)$. The turbulence measurements at elevated heights (EC at BT Tower, LAS) complement the lidarderived turbulent mixing properties of the urban boundary layer. Figure 4 shows the median diurnal patterns of $Q_{H}$ (solid lines), with the interquartile range shaded. Overall, $Q_{H}$ is higher in summer than in winter, which is consistent with the higher summer MHs shown in Fig. 3. The diurnal patterns are clearly related to the energy available from the net all-wave radiation $Q^{*}$ (diamonds).

At sites observing energy exchanges at the local scale (EC at KSS, KSSW; LAS), the nocturnal sensible heat flux is positive-that is, transporting energy away from the surface-even in winter. This is driven by considerable storage and anthropogenic heat fluxes within the respective local-scale source areas (Kotthaus and Grimmond 2014b). The morning peak (around 0700 UTC) at KSS is presumably due to local anthropogenic heat emissions (Kotthaus and Grimmond 2012). Both anthropogenic and storage heat fluxes appear to be weaker in the footprint of the WCC site, where nocturnal sensible heat fluxes become negative during winter. At BT Tower, the fluxes respond to a larger footprint (Wood et al. 2009), and the sign of the median sensible heat flux is more variable: the flux is slightly negative or zero during the early morning hours in winter and summer. The areal extent of the LAS systems footprints, depends like the EC sensors, on the height of the instruments, the meteorological conditions, the roughness characteristics but there is the additional areal extent because of the distance between the source and receiver (see Ward et al. 2013 for comparison of EC and LAS footprints).

Given the dependence on available energy from radiative forcing, the morning increase of $Q_{H}$ occurs earlier in the summer. Accordingly, the $\mathrm{MH}$ grows later and breaks down earlier in winter than in summer. The smaller $Q^{*}$ in winter reduces the convective forcing and consequently the $\mathrm{MH}$ grows at a lower rate after the morning transition (Fig. 3). During both IOPs sensible heat flux estimates at all sites keep increasing after $Q^{*}$ declines. This contributes to the deeper $\mathrm{MH}$ over London at night compared to the rural surroundings.

The $Q_{H}$ measurements at different heights aid interpretation of the diurnal and seasonal changes in the turbulent mixing within the lowest $200 \mathrm{~m}$ of the urban boundary layer: during daytime in summer, $Q_{H}$ on BT Tower lies within the interquartile range (IQR) of $Q_{H}$ from the other stations, suggesting that this elevated measurement height is still located within the constant flux layer. In winter, however, $Q_{H}$ on BT Tower is outside the IQR during large periods of the day, especially at nighttime, and increases after the morning transition an hour later than near the surface. The vertical profile of $Q_{H}$ decays more quickly with height in winter than in summer. Presumably, BT Tower observations during winter often represent 


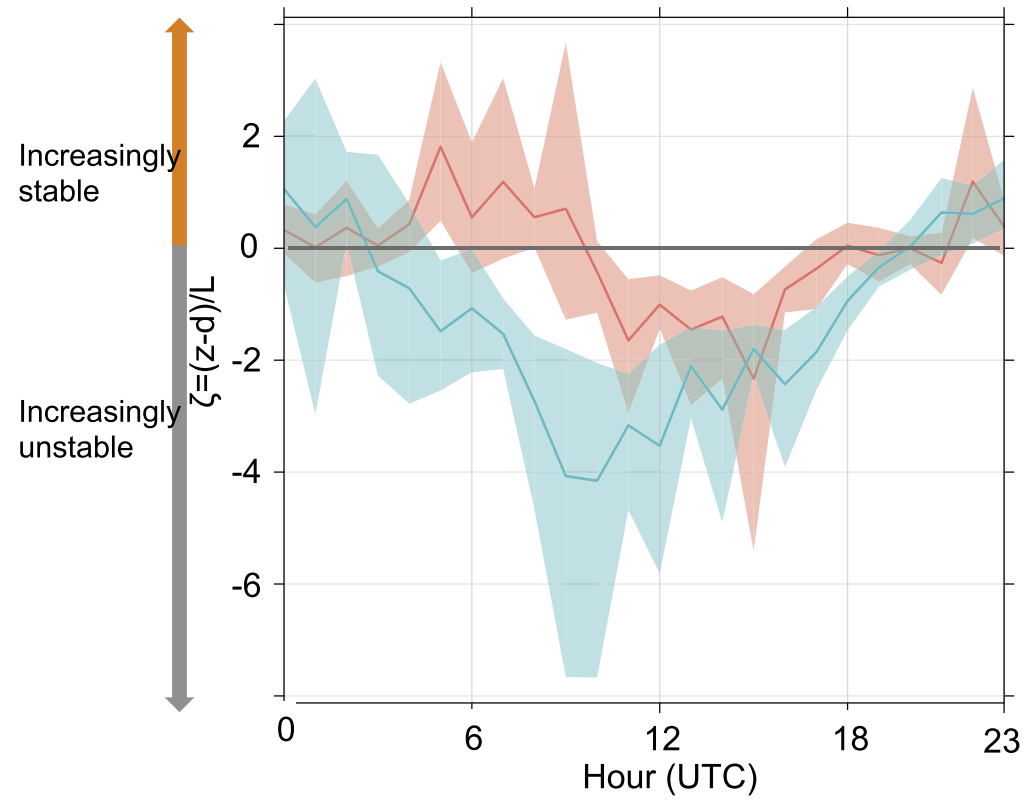

FIG. 5. Mean diurnal cycle of local Obukhov stability length $\zeta=\left(z_{B T}-d\right) / L$ based on 30-min-averaged EC measurements at the top of BT Tower during the summer (blue line) and winter (red line) IOP. Shaded areas indicate the $5^{\text {th }}$ - and $95^{\text {th }}$-percentile ranges. Zero plane displacement height $d$ is chosen according to Wood et al. (20l0).

a different atmospheric layer compared to the other instruments at lower heights. Probably BT Tower is either in the well-mixed layer, where the heat flux decreases with height, or in a residual layer (Wood et al. 2010). This idea is consistent with the diurnal pattern of the local Obukhov stability parameter $\zeta$ calculated from BT Tower data (shown in Fig. 5) following Wood et al. (2010). The values of $\zeta$ at this elevated height are indicative of the probable origin: $\zeta>0.1$ indicates stable conditions with suppressed turbulent mixing; $\zeta<-0.1$ indicates unstable conditions with convective turbulent mixing. Thus, the sign of $\zeta$ indicates if measured pollutant concentrations are representative of an urban area in London or of background air from rural surroundings or a residual layer.

According to Fig. 5, BT Tower is located in a convective boundary layer and connected to the surface most of the time in summer, and in a weakly stable residual layer only during the early morning hours in summer and during nighttime and large parts of the morning in winter. However, the range (illustrated by shading in Fig. 5) indicates that BT Tower is occasionally located in the convectively driven layer even during nighttime in winter. Locally stable conditions on BT Tower can refer to two different boundary layer states. BT Tower might be in a weakly stable layer due to radiative cooling from the surface. This, however, seems unlikely given the observed low probability of negative surface sensible heat fluxes (Fig. 4). It seems more likely that the BT Tower site lies above the boundary layer. In such cases, the BT Tower measurement height is decoupled from the local-scale surface.

Crucially for air quality, according to the observations (Figs. 3-5), the $\mathrm{MH}$ starts to grow well before the morning rush-hour peak in summer, so that traffic-induced emissions peak when the $\mathrm{MH}$ is already deep. In winter the $\mathrm{MH}$ starts to grow after the morning emissions peak. Hence, we would expect a rapid rise in concentrations of traffic-induced pollution as emissions peak in a shallower mixed layer.

Urban increment and seasonal changes in $\mathrm{CO}$ and reactive gases. $\mathrm{CO}$ and $\mathrm{O}_{3}$ are air pollutants with relatively long atmospheric lifetimes, around 2 months and 1 week, respectively. Such lifetimes allow for transport of pollutants on hemispheric and regional scales, respectively. Exposure to $\mathrm{O}_{3}$ in urban areas is particularly affected by the inflow of $\mathrm{O}_{3}$ from the regional/background atmosphere, climatologically in the United Kingdom from the (southeastern) Atlantic. Urban production or destruction of $\mathrm{O}_{3}$ takes place on this background. Concentrations of CO have decreased markedly as an air pollutant in the United Kingdom since 1990, and are generally below air quality limit values (von Schneidemesser et al. 2010). CO is a good tracer for pollution on both regional and local scales, and is a sink of $\mathrm{OH}$ and is therefore measured in ClearfLo. Similar to $\mathrm{O}_{3}$, the urban emissions of $\mathrm{CO}$ can only be evaluated once the background import is accounted for.

As part of ClearfLo, the urban increments in $\mathrm{CO}$ and $\mathrm{O}_{3}$ are determined by comparing measurements at NK and Chilbolton. The latter is associated with only minor local sources of $\mathrm{CO}$ and represents the regional background of $\mathrm{CO}$ and $\mathrm{O}_{3}$ that can flow into London. Hourly $\mathrm{O}_{3}$ mixing ratios at $\mathrm{NK}$ differ most from Chilbolton during winter (December 2011-February 2012) according to the data in Fig. 6. Mixing ratios of $\mathrm{O}_{3}$ in winter are skewed toward lower values at $\mathrm{NK}$ and higher values at Chilbolton, reflecting urban "titration" (loss) of $\mathrm{O}_{3}$ via reaction with NO. In summer (June-August 2012), the rural 
background dominates $\mathrm{O}_{3}$ at NK despite the presence of $\mathrm{O}_{3}$ precursor anthropogenic emissions. There were only a few episodes where photochemical production in London led to elevated concentrations that are not entirely dominated by the rural background. In the rural and urban regions of the United Kingdom, $\mathrm{CO}$ is likely to be anthropogenic in origin; hence, we have used $\mathrm{CO}$ as an indicator for anthropogenic $\mathrm{O}_{3}$ precursors (von Schneidemesser et al. 2010). The histograms for CO show more frequent polluted episodes at NK than at Chilbolton (Fig. 7). This difference is most evident in winter, when the $\mathrm{MH}$ is shallower and pollutants are mixed within a smaller volume. The differences between NK and Chilbolton highlight the importance of traffic emissions on air pollution in London.

Averaged diurnal cycles over the IOP periods for $\mathrm{NO}, \mathrm{NO}_{2}, \mathrm{NO}_{x}, \mathrm{CO}$, and $\mathrm{O}_{3}$ alongside incoming solar radiation indicating the diurnal range for NK are shown in Figs. 8 and 9. In general, mixing ratios are much higher in winter than in summer except for $\mathrm{O}_{3}$ at $\mathrm{NK}$. $\mathrm{NO}, \mathrm{NO}_{2}, \mathrm{NO}_{x}$, and $\mathrm{CO}$ peak during the morning and again rise slightly during evening rush hour. This is the typical behavior of an urban background site (Bigi and Harrison 2010). CO shows a much more pronounced morning peak in winter than in summer and $\mathrm{NO}_{x}$ is doubled in winter. $\mathrm{NO}, \mathrm{NO}_{2}$, $\mathrm{CO}$, and $\mathrm{NO}_{x}$ peak around $2 \mathrm{~h}$ earlier in summer (at 0700 UTC) than in winter. An hour offset between the periods is owing to the change from British summer time to UTC in the winter-the summer peak is at 0700 UTC (0800 local time) and in winter the peak is at 0900 UTC (local time) - with the rest likely owing to changes in mixing properties between summer and winter as shown in the "Urban increment in boundary layer meteorology" section, rather than primary emissions. The morning peak in primary pollutants is more pronounced because of increased traffic volume and less turbulent mixing/lower $\mathrm{MH}$ and therefore poorer dispersion of pollutants. (a)

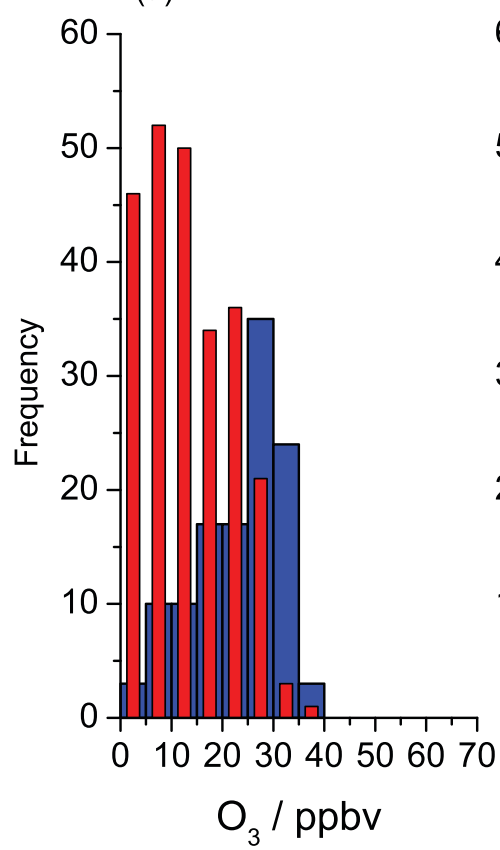

(b)

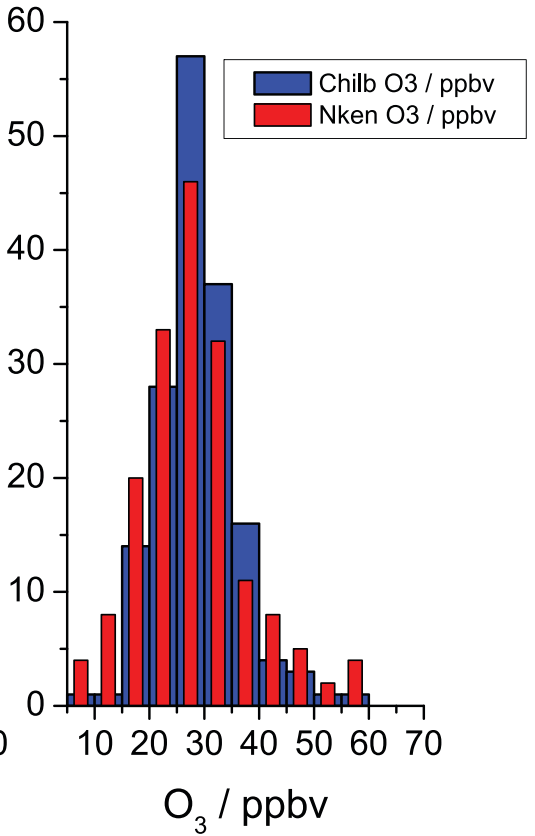

FIG. 6. Histogram of 5-min-averaged surface measurements of $\mathrm{O}_{3}$ at Chilbolton (blue) and North Kensington (red) based on long-term measurements for (a) winter season (Dec 20II-Feb 20I2) and (b) summer season (Jun-Aug 20I2). See Tables ESI-ES3 for details on measurement location and instruments.

(a)

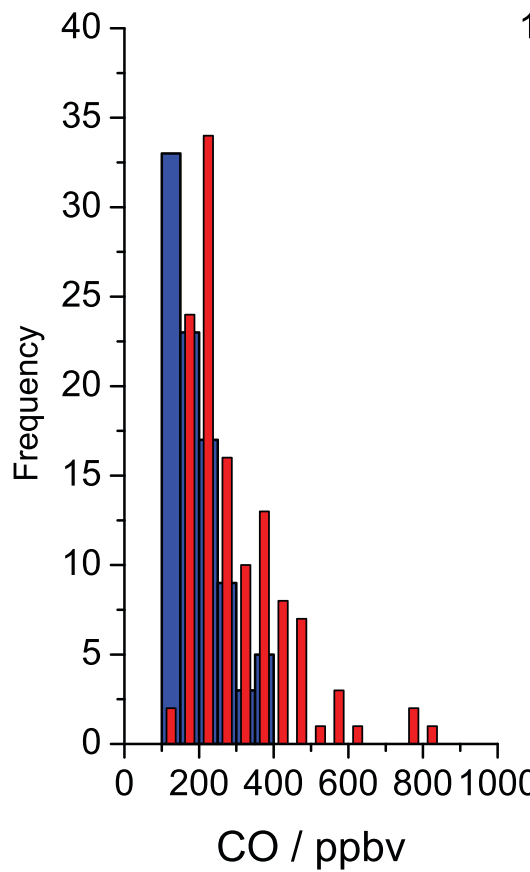

(b)

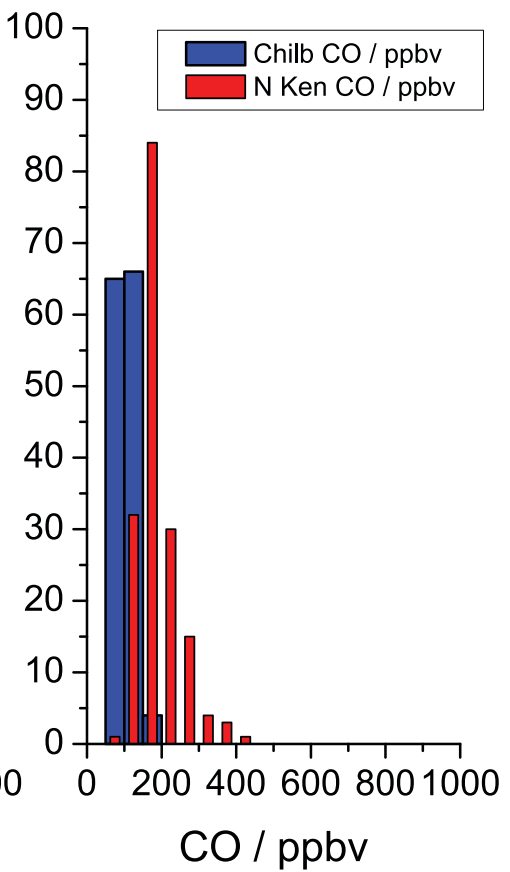

Fig. 7. As in Fig. 6, but for CO. Please note the different scales. 
Increased photochemical production in the summer leads to higher $\mathrm{O}_{3}$ concentrations. While $\mathrm{O}_{3}$ is nearly completely titrated by its fast reaction with NO during the morning rush hour in winter, we still observe $\mathrm{O}_{3}$ during the morning rush hour in summer. While daytime and nighttime $\mathrm{O}_{3}$ concentrations do not differ strongly in winter, daytime concentrations in summer are much higher than in winter. The seasonal differences in the evening concentrations for NO highlight the increased turbulent mixing and dilution effect of the deeper MH (see the "Urban increment in boundary layer meteorology" section) in summer and larger summertime photochemical losses for $\mathrm{NO}_{x}$ into nitric acid.

Scatterplots of $\mathrm{NO}, \mathrm{NO}_{2}$, and $\mathrm{O}_{3}$ against total $\mathrm{NO}_{x}$ demonstrate the different photochemical regimes in winter and summer (Fig. 10), similar to Clapp and Jenkin (2001) for London. Winter is dominated by high $\mathrm{NO}_{x}$ and the negligible production of $\mathrm{O}_{3}$, with a clear and well-defined anticorrelation between $\mathrm{NO}_{x}$ and $\mathrm{O}_{3}$ due to titration of $\mathrm{O}_{3}$ by the reaction with
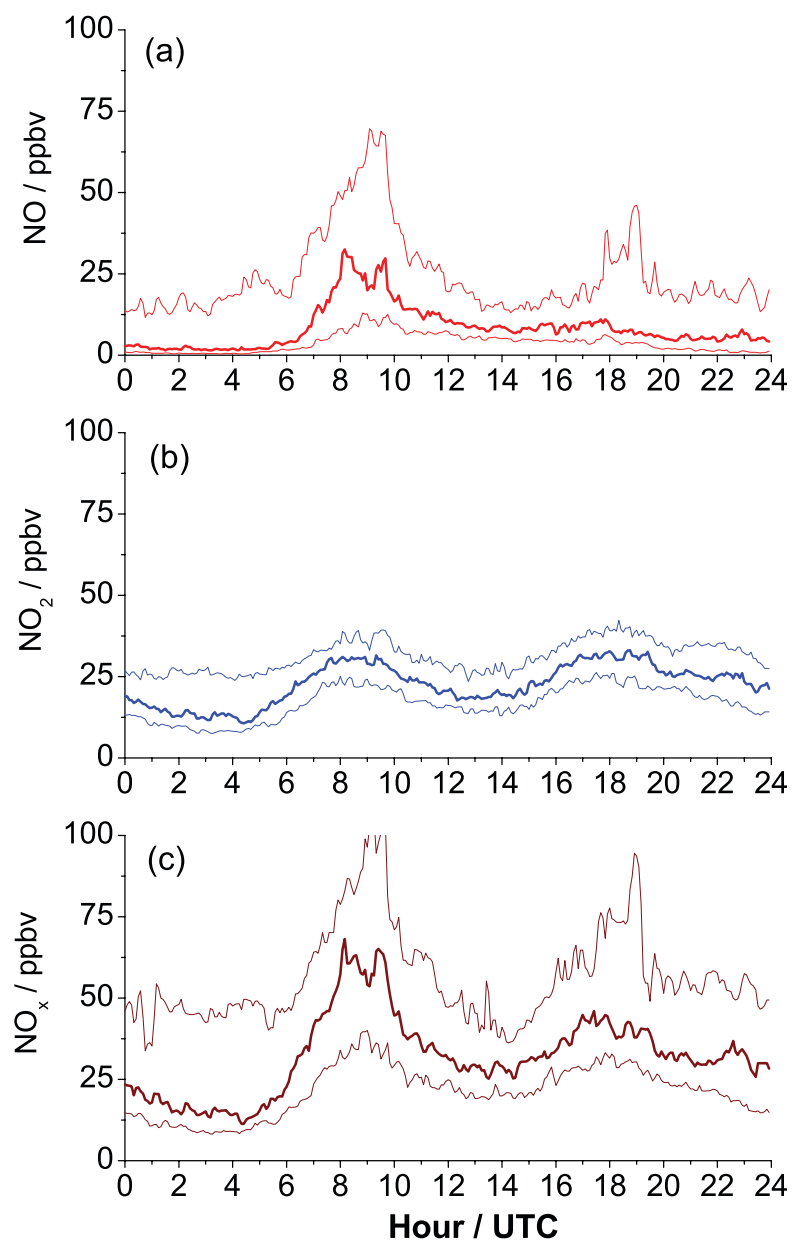

$\mathrm{NO}$ and the lack of sunlight, which would cause photolysis of $\mathrm{NO}_{2}$ back to $\mathrm{NO}$, with the subsequent reformation of $\mathrm{O}_{3}$. In summer, $\mathrm{NO}_{x}$ levels are lower (mainly because of meteorological conditions) and there is a less clear relation between $\mathrm{NO}_{x}$ and $\mathrm{O}_{3}$. This is in part due to more sunlight being available to repartition oxidant to $\mathrm{O}_{3}$ via photolysis of $\mathrm{NO}_{2}$. This leads to the much higher $\mathrm{O}_{3}$ concentrations than are observed for equivalent $\mathrm{NO}_{x}$ levels compared to winter. Also, in summer the $\mathrm{NO}$-to- $\mathrm{NO}_{2}$ ratio is potentially perturbed by the higher formation rates of peroxy radicals $\left(\mathrm{RO}_{2}\right)$ formed from various volatile organic compounds (VOCs), including the very reactive biogenic hydrocarbons providing another route to oxidize $\mathrm{NO}$ to $\mathrm{NO}_{2}$ conversion and hence lead to $\mathrm{O}_{3}$ formation.

Figure 11 shows the urban increment and spatial variability of the IOP-averaged $\mathrm{NO}_{x}$ concentrations as calculated by the Community Multiscale Air Quality (CMAQ) modeling system forced by meteorological input fields simulated by the Weather Research and
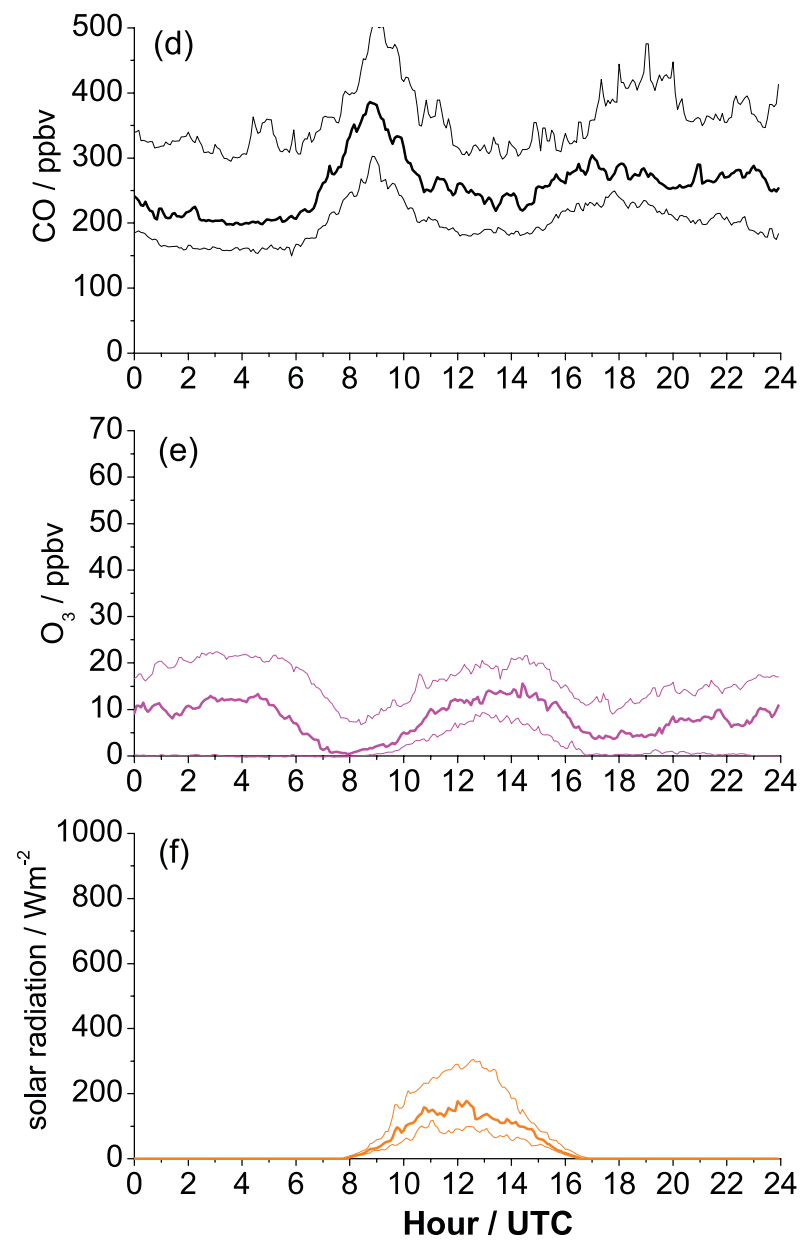

FIG. 8. The 5-min-averaged diurnal cycle for (a) $\mathrm{NO}$, (b) $\mathrm{NO}_{2}$, (c) $\mathrm{NO}_{x}$, (d) $\mathrm{CO},(\mathrm{e}) \mathrm{O}_{3}$, and (f) solar radiation at NK during the winter IOP. Thick lines correspond to the median and thin lines are the corresponding quartiles. 

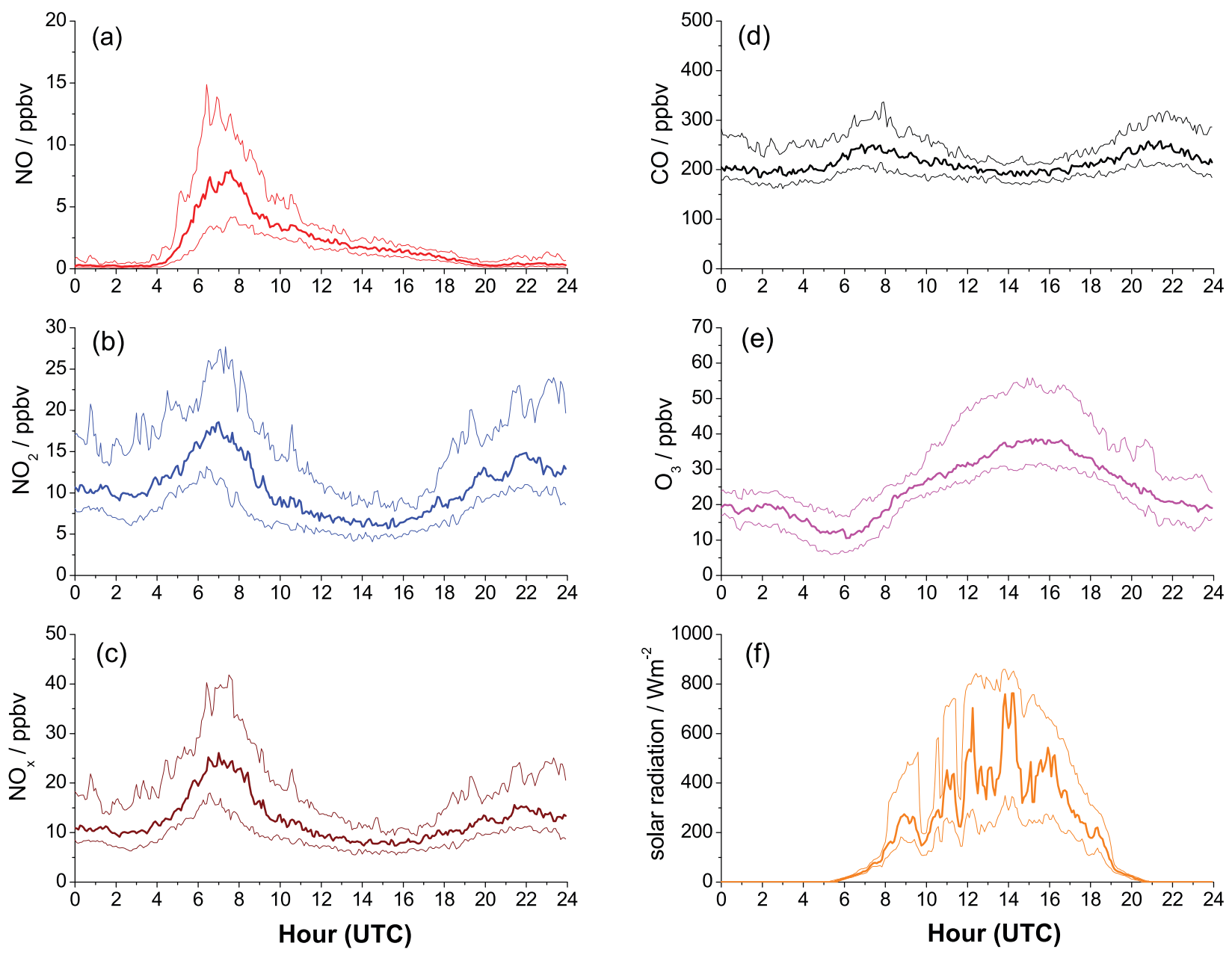

FIG. 9. As in Fig. 8, but for the summer IOP.

(a)

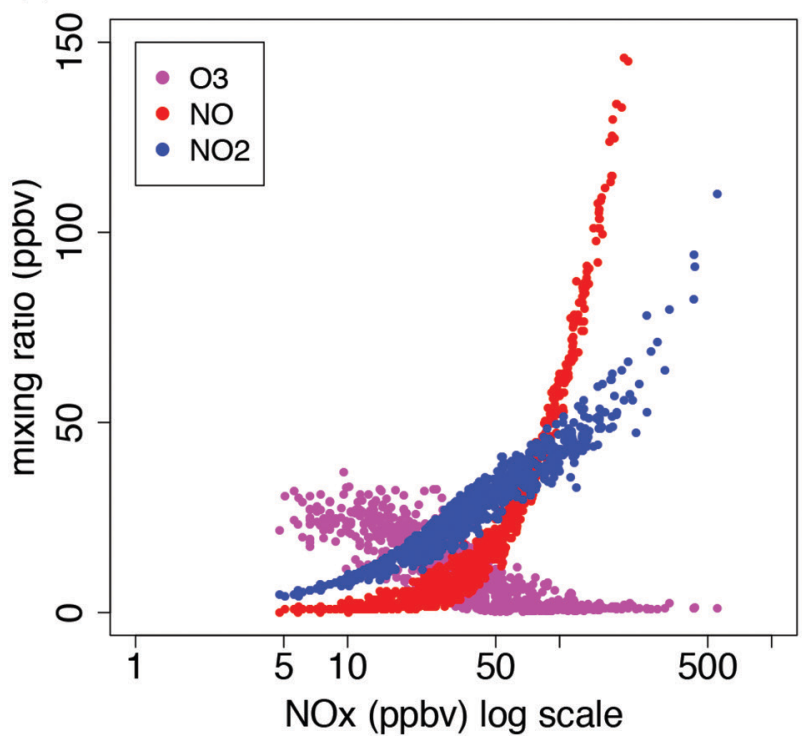

(b) summer IOP

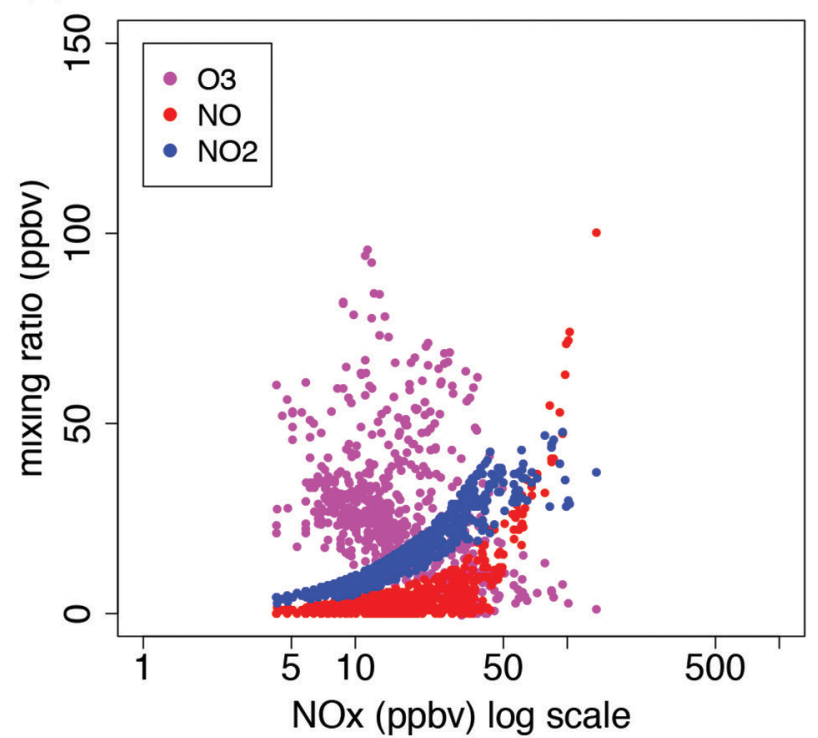

FIG. I0. NO, $\mathrm{NO}_{2}$, and $\mathrm{O}_{3}$ as a function of total $\mathrm{NO}_{x}$ at $\mathrm{NK}$ on a log scale for (a) winter IOP and (b) summer IOP based on hourly averaged mixing ratios. 


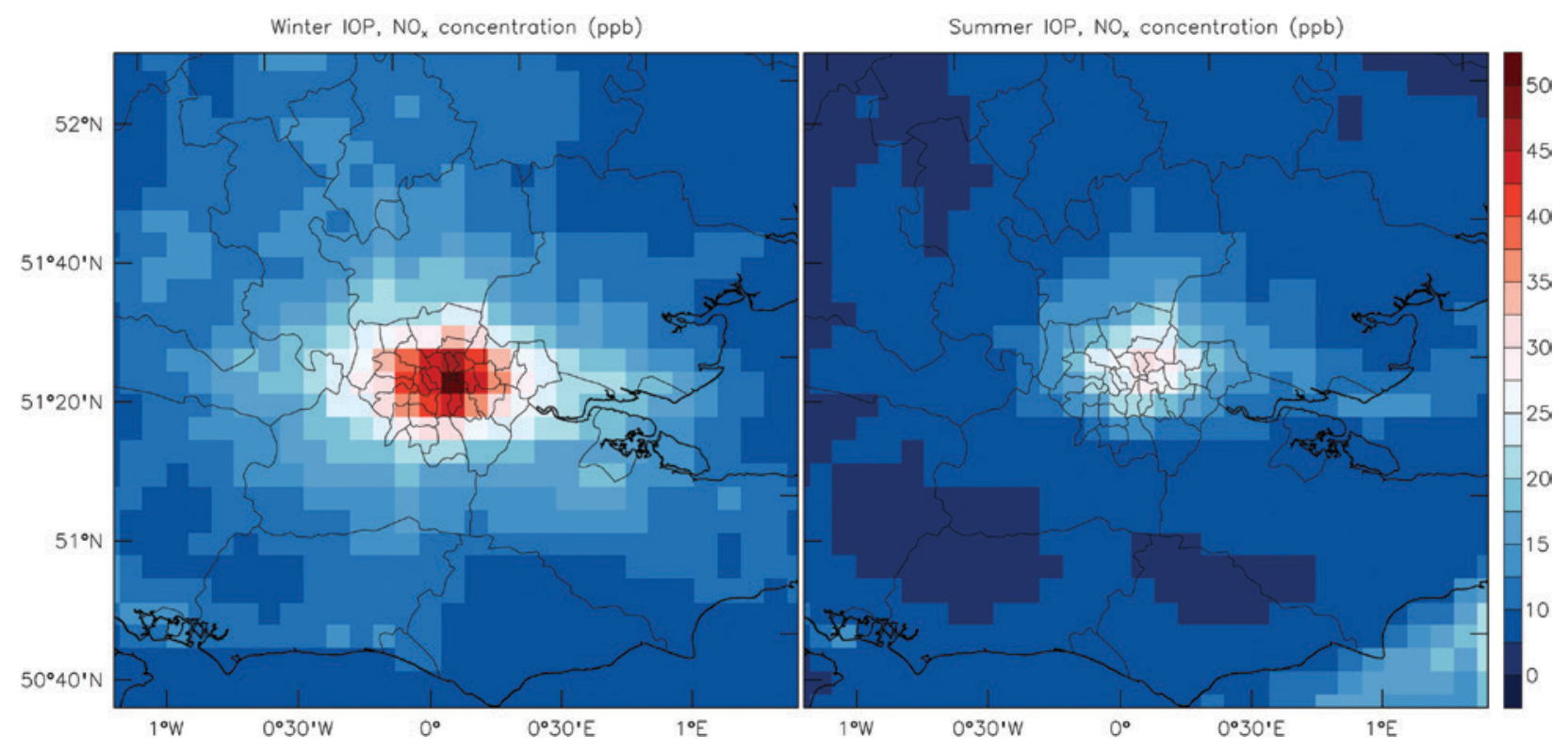

FIG. II. Mean NO concentrations from midlayer height of the first model grid box at $12.5 \mathrm{~m}$ above ground at a horizontal resolution of $6 \mathrm{~km}$ calculated using WRF-CMAQ simulations for (left) winter and (right) summer IOP periods. Thick black lines indicate southern U.K. land-sea mask and thin black lines indicate counties, with Greater London in the center of the domain.

Forecasting (WRF) Model to account for London's impact on the atmosphere. The CMAQ modeling system configuration is used by Appel et al. (2012) for the first phase of the Air Quality Model Evaluation International Initiative (AQMEII) with the addition of nested domains over the United Kingdom and southeast of England. CMAQ accounts for the distribution of emissions sources, long-range transport, and the ability of London's atmosphere to dilute pollutants. The CMAQ modeling system has been evaluated thoroughly in previous studies over the United Kingdom (e.g., Chemel et al. 2010) and Europe (e.g., Appel et al. 2012). The long-term numerical simulations with the CMAQ modeling system are complemented by case studies with the Air Quality in the Unified Model (AQUM) during the IOPs and the variable-resolution U.K. model (UKV) representing the urban surface energy balance with the Met Office-Reading Urban Surface Exchange Scheme (MORUSES) set up for London (Bohnenstengel et al. 2011). These will provide a detailed picture of the processes driving the spatial and temporal distribution of the urban increment, and will help interpret the measurements in the larger-scale atmospheric context and will be reported in future papers.

VOCs in London. In an effort to understand the differences between the summer and winter photochemical regimes shown in Fig. 10, we measured an extensive range of gas-phase species, which provide additional routes to $\mathrm{O}_{3}$ formation and depletion. For example, the oxidation of VOCs by OH leads to the formation of $\mathrm{RO}_{2}$ and $\mathrm{HO}_{2}$ radicals. During daytime the reaction of $\mathrm{HO}_{2}$ or $\mathrm{RO}_{2}$ with $\mathrm{NO}$, whose concentration is elevated in urban areas because of traffic emissions, leads to the in situ production of $\mathrm{O}_{3}$ through photolysis of the resulting $\mathrm{NO}_{2}$. Theory suggests that net $\mathrm{O}_{3}$ production from these peroxy radical-NO reactions should decrease as $\mathrm{NO}_{x}$ increases to more than a few parts per billion by volume (ppbv), due to the reaction of $\mathrm{OH}$ with $\mathrm{NO}_{2}$ (to form soluble $\mathrm{HNO}_{3}$ ) and the production of organic nitrates terminating the cycle. Therefore, in an urban environment such as London, high levels of $\mathrm{NO}_{x}$ can suppress $\mathrm{O}_{3}$ production, especially during the winter when photolysis levels are low. The amount and $\mathrm{OH}$ reactivity of the VOCs present is crucial with $\mathrm{O}_{3}$ production being often limited by VOC loading in urban environments.

The VOCs were measured during the IOPs at the NK, MR, and KSSW sites. Two different gas chromatographs (GC) were deployed: a dual-channel GC and a comprehensive two-dimensional GC for $\mathrm{C}_{2}-\mathrm{C}_{8}$ and $\mathrm{C}_{5}-\mathrm{C}_{14}$ VOCs, respectively. Comeasurement of a number of compounds allows for direct comparison of the instruments and observations, and agreement between the two techniques is excellent. Additionally, nine targeted VOC mixing ratios and short scans of the whole mass range $(m / z 19-205)$ were quantified by PTR-MS at the NK, MR, and Detling sites during the winter IOP. Flux measurements of 

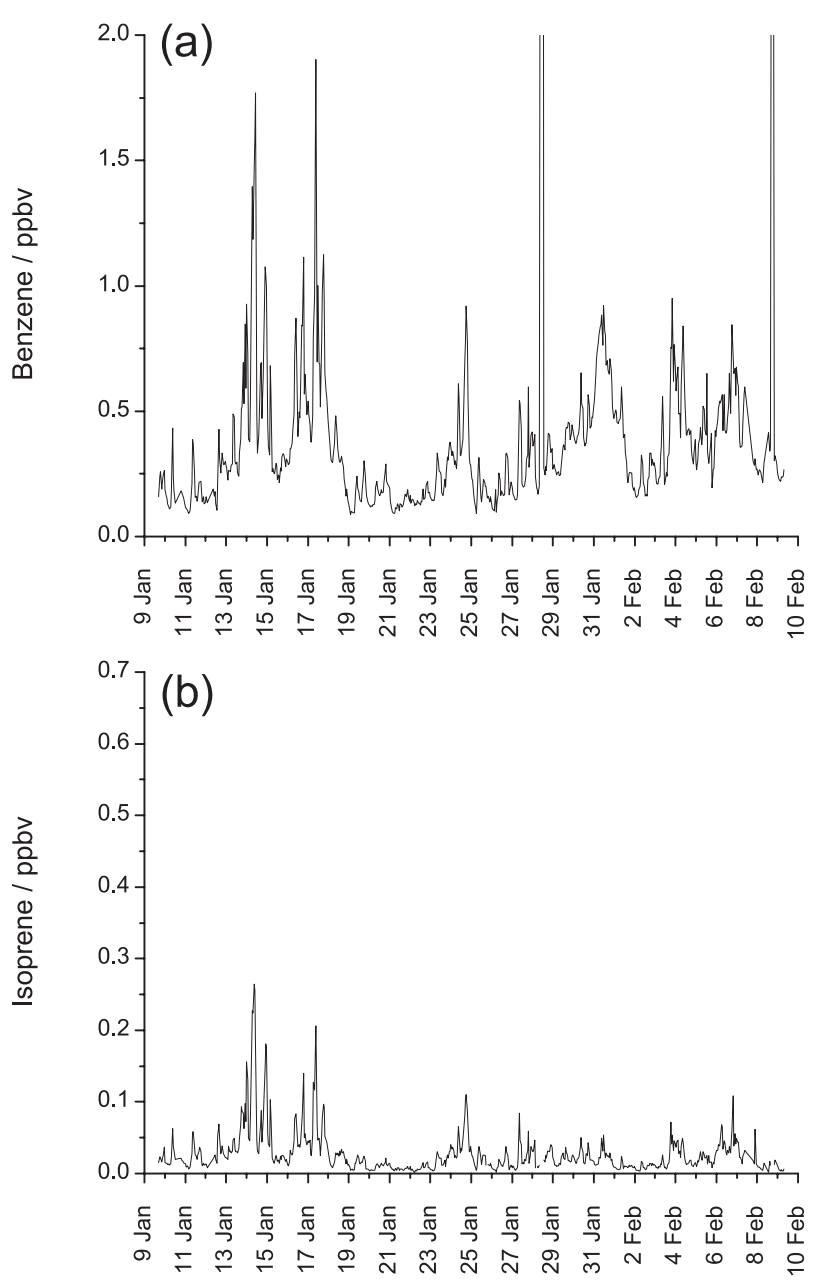

Date

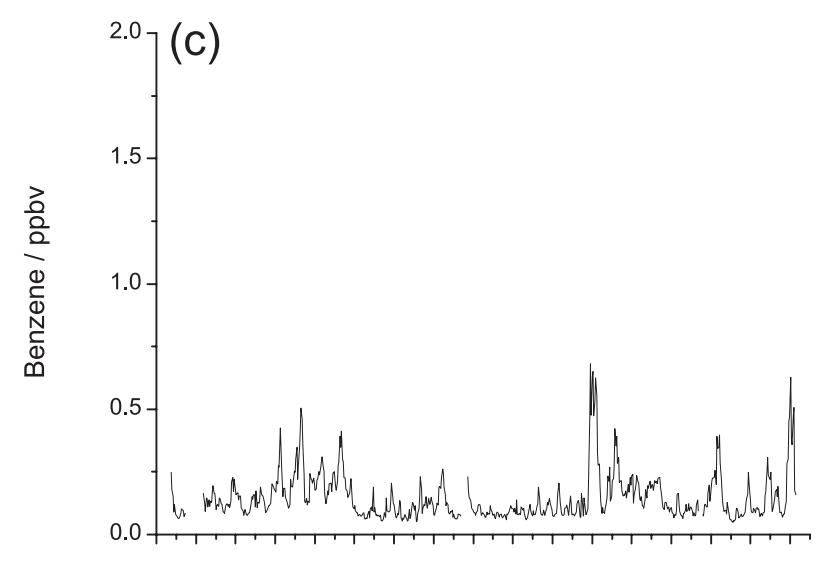

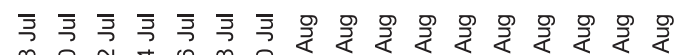

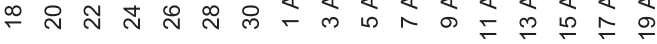

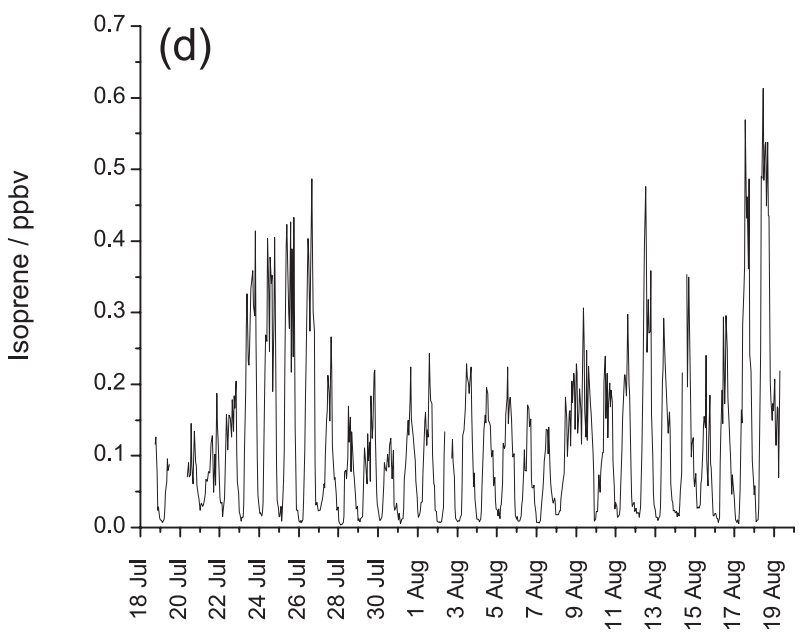

Date

FIG. I2. Surface benzene concentrations during (a) winter IOP and (b) summer IOP, and isoprene concentrations during (c) winter IOP and (d) summer IOP at NK.

the same compounds and mass range concentrations were also recorded from the KSSW site from August to December 2012, which overlapped with the summer IOP. PTR-MS measurements at MR allow for a direct comparison of several compounds $\left[\mathrm{m} / \mathrm{z} 79\right.$ (benzene), 93 (toluene), 107 ( $\mathrm{C}_{2}$-Benzenes), and $121\left(\mathrm{C}_{3}\right.$-Benzenes)] with measurements from the GC-FID of the Automatic Hydrocarbon Network run by the Department for Environment, Food and Rural Affairs (Defra), which show good qualitative agreement (correlation $r$ between 0.90 and 0.91 ) and linear correlations with collocated CO measurements that are higher for PTR-MS than for GC-FID (Valach et al. 2014).

Figure 12 shows a time series plot of two selected VOCs, benzene of mainly anthropogenic origin and isoprene of mainly biogenic origin, for both the winter and summer IOPs at NK. The mixing ratio of benzene in winter is observed to be around double that of summer, consistent with a longer winter lifetime with respect to $\mathrm{OH}$ and the generally lower $\mathrm{MH}$ relative to summertime conditions observed by the lidars (see the "Urban increment in boundary layer meteorology" section). Under certain conditions, morning and afternoon rushhour peaks are observed for benzene, consistent with its traffic-related source, but these are masked by synoptic-scale changes in weather. The majority of other anthropogenic VOCs measured during the campaigns follow profiles similar to that of benzene. Mixing ratios of isoprene, mainly biogenic in origin, behave very differently, and are observed to be much higher during the summer IOP, with average mixing ratios around 5 times greater than those during 
winter. This is consistent with the observed increase in photosynthetically active radiation and warmer temperatures, leading to increased emissions from vegetation. The wintertime observations of isoprene are generally well correlated with benzene, indicating a small tail-pipe anthropogenic source. This relationship is not observed during the summer IOP, when the diurnality of the biogenic activity and the reaction of isoprene with $\mathrm{O}_{3}$ during the day and with $\mathrm{NO}_{3}$ at night, which deplete isoprene to very low levels after sunset, determines its behavior (von Schneidemesser et al. 2011). These observations are consistent with the findings of Langford et al. (2010), whose analysis of automatic hydrocarbon data from the MR site suggested that over $60 \%$ of the observed isoprene at this site was of a biogenic origin at temperatures exceeding $20^{\circ} \mathrm{C}$. Measurements over the full carbon range of gas-phase species indicate that considerable mass loading of higher hydrocarbons, greater than eight carbons, is present in both summer and winter.

$\mathrm{OH}, \mathrm{HO}_{2}, \mathrm{RO}_{2}$, and $\mathrm{OH}$ reactivity were measured using the fluorescence assay by gas expansion (FAGE) technique (Stone et al. 2012), with some speciation of $\mathrm{RO}_{2}$ determined between those derived from light alkanes and those derived from longer-chain alkanes, alkenes, and aromatic parent species (Whalley et al. 2013). The levels of radicals, in particular OH, are considerably higher during the summer campaign compared to winter, owing to the greater level of photochemical production. The radicals are dependent on $\mathrm{NO}_{x}$ and are highest on warmer days when higher levels of $\mathrm{O}_{3}$ are experienced. Significant local production of $\mathrm{O}_{3}$ is observed during the summer campaign in London, and the radical measurements enable the fraction of $\mathrm{O}_{3}$ that is generated locally, rather than being advected to the site, to be determined, and also a partial breakdown of the classes of VOCs that are responsible for $\mathrm{O}_{3}$. The total $\mathrm{OH}$ reactivity is found to reach as high as $100 \mathrm{~s}^{-1}$, and its magnitude and daily structure are reproduced well by a numerical model using the master chemical mechanism (Jenkin et al. 1997) and constrained by the VOC measurements.

Urban increment in particulate matter and its size distribution. Many complex processes contribute to the particulate burden, and PM can exhibit a strong urban increment. As well as primary particulates directly emitted to the atmosphere (e.g., in vehicle exhausts, from cooking and domestic burning, dust from transport- and marine-generated particles), there are also secondary particulates formed from the oxidation of gas-phase species. While current legislation is based around the total mass of particulates (specifically the $\mathrm{PM}_{10}$ and $\mathrm{PM}_{2.5}$ standards), greater insight into the processes controlling the burden can be obtained by inspecting the different chemical components separately. BC, or soot, is composed of small particles $\left(\mathrm{PM}_{1}\right)$, emitted by combustion sources and is largely inert once in the atmosphere, so it can be expected to correlate with other primary combustion pollutants such as $\mathrm{NO}_{x}$ and $\mathrm{CO}$ at a receptor site. Conversely, particulate nitrate and sulfate are formed from the secondary oxidation of $\mathrm{NO}_{x}$ and $\mathrm{SO}_{2}$, respectively, and behave in a more complex manner. The particulate organics consist of a mixture of primary emissions and secondary matter formed from the oxidation of VOCs (see the "VOCs in London" section) from different sources, and they present a challenging subset to study.

To determine strategies to reduce PM concentration in urban areas, there is a need to identify the underlying sources through source apportionment methodologies based on the physicochemical composition of the PM at urban and rural locations. Figure 13 shows the monthly variation in the chemical composition of PM at NK in 2011 and 2012. Organic aerosol is the most abundant (35\%) followed by secondary inorganic aerosols, such as nitrate (18\%), sulfate (11\%), and ammonium (9\%), with smaller contributions from marine aerosol components, such as chloride (7\%) and sodium (4\%), and combustion emissions, such as elemental carbon. The elemental carbon tracer method (Turpin and Huntzicker 1995) is used to apportion the organic aerosol into primary versus secondary. Analysis of aerosol mass spectrometer (AMS) data indicates that $11 \%$ is vehicle exhaust related, while the remainder is from other local sources such as solid fuel burning and cooking (Allan et al. 2009) and oxidized organic aerosol from more distant sources. Peak $\mathrm{PM}_{10}$ concentrations are principally encountered in the springtime, when emissions of primary precursors for secondary inorganic aerosol $\left(\mathrm{NO}_{2}\right.$ and $\left.\mathrm{SO}_{2}\right)$ from fossil fuel heating are still elevated because of cold weather, agricultural activity gives a high ammonia background-in particular, European fertilizer spreading-and oxidation rates are increasing because of higher actinic fluxes. Importantly, the lower ambient temperatures favor the partitioning of semivolatile ammonium nitrate into the particle phase. During these periods, anticyclonic conditions are also common, advecting polluted air from continental Europe into the southeast of the United Kingdom and adding to London's local pollution emissions. The contribution of regional sources to the $\mathrm{PM}_{10}$ concentration measured in urban 

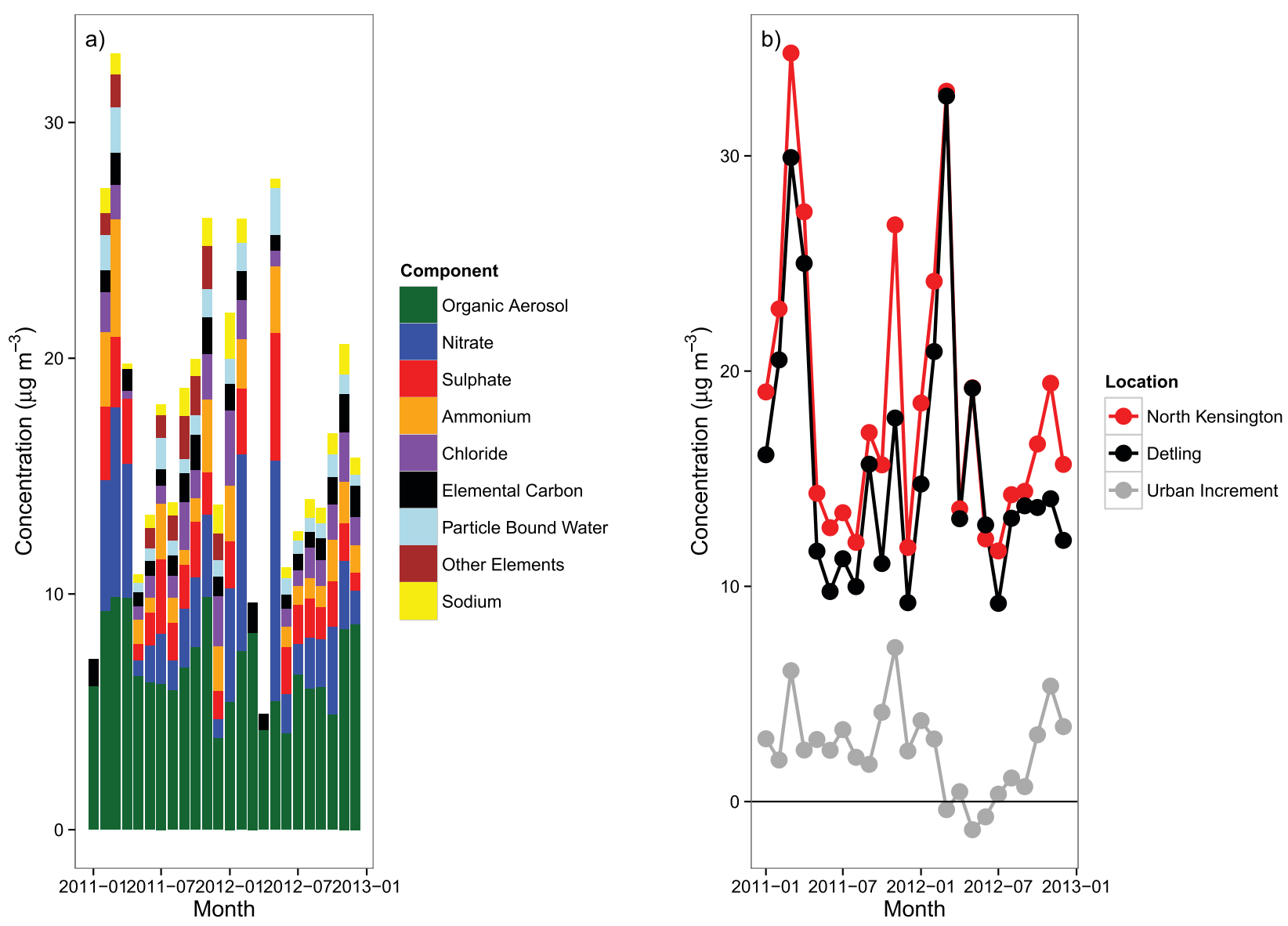

FIG. 13. (a) Chemical composition of $\mathrm{PM}_{10}$ during Jan $201 \mathrm{I}-J a n 2013$ at NK. (b) Mass concentration of $\mathrm{PM}_{10}$ measured at NK, Detling, and the resulting urban increment in $\mathrm{PM}_{10}$ for the two years (20II-13) measured using online ion chromatography (anions and cations), thermal-optical (elemental and organic carbon), and hydrofluoric acid (HF) digest and inductively coupled plasma mass spectrometry (ICP-MS) analysis (metallic elements).

background locations in London is illustrated in Fig. 13b, showing $\mathrm{PM}_{10}$ mass concentrations at NK, Detling, and the urban increment. Similarly, elevated springtime concentrations are experienced at both rural and urban locations. Local emissions have a greater impact in the winter, when reduced MHs lead to a buildup of primary pollutants such as elemental carbon and primary organic emissions, which increases the urban increment between October and February. Additionally, carbon-14 $\left({ }^{14} \mathrm{C}\right)$ analyses of $\mathrm{PM}_{1}$ and $\mathrm{PM}_{2.5}$ samples collected during the IOPs will enable insight into the proportion of fine carbonaceous aerosol derived from sources of contemporary and fossil carbon (Heal 2014 and references therein). The proportion of contemporary carbon in both the total carbon and the organic and elemental carbon components is determined separately. Early results suggest that a large proportion of the carbonaceous $\mathrm{PM}_{2.5}$ is nonfossil in origin with no obvious summerwinter difference in the proportion of contemporary carbon at the NK site.
$\mathrm{BC}$, measured using optical transmission through a filter, is often used as an indicator of vehicle, especially diesel engine activity, but is also associated with other forms of combustion such as biofuel burning. During the campaign precise and accurate direct measurements of the ultrafine particles $\left(\mathrm{PM}_{1}\right)$ were made using a single-particle-laser-induced incandescence instrument [single-particle soot photometer (SP2)] at NK and Detling (Schwarz et al. 2010). It is a pollutant that is, in part, amenable to regulatory control and also contains potentially toxic components such as polycyclic aromatic hydrocarbons (PAHs) and metals in a fine particle mode that can reach the lungs through the nasal tract, so a health response could be expected. Figure 14 compares the averaged diurnal cycle of BC for both IOPs for NK, Detling, and Harwell. The aetholometer and SP2 BC results in Detling agree with an indication that most of the $\mathrm{BC}$ is in fine $\mathrm{PM}_{1}$ particles. Detling sits between the M2 and M20 motorways about $50 \mathrm{~km}$ from central London, and depending on wind direction 
it is directly influenced by motorway traffic and the nearby town of Maidstone. It is strongly influenced by biofuel burning in winter (Mohr et al. 2013), as is evident in the larger $\mathrm{BC}$ values of approximately $1 \mu \mathrm{g} \mathrm{m}^{-3}$ that we measured.

BC concentrations at Harwell and Detling increase toward the evening in winter, but they only increase slightly in summer, which could be indicative of rural domestic burning. A similar influence was noted at the rural Holme Moss site near Manchester by Liu et al. (2011). In winter, rural BC concentrations show a single evening peak. The 3-h delay at Harwell may be caused by the time it takes to advect $\mathrm{BC}$ into the rural background from other conurbations; alternatively, the relative importance of other sources (such as solid fuel burning for domestic heating) at Harwell and Detling may contribute to the difference in diurnal cycles. In summer a two-peak distribution is measured at Detling, probably because as the influence of domestic burning diminishes after the winter, the diurnal cycle is more strongly dominated by other combustion activities.

Concentrations of $\mathrm{BC}$ at NK follow a pronounced diurnal pattern similar to $\mathrm{NO}_{x}$ (see the "Urban increment and seasonal changes in $\mathrm{CO}$ and reactive gases" section). The urban increment leads to levels 3 times those in the rural background during rush-hour traffic periods, which will be due to a combination of traffic and domestic burning sources. Part of the phase shifts between winter and summer will be due to a change to daylight saving time [British summer

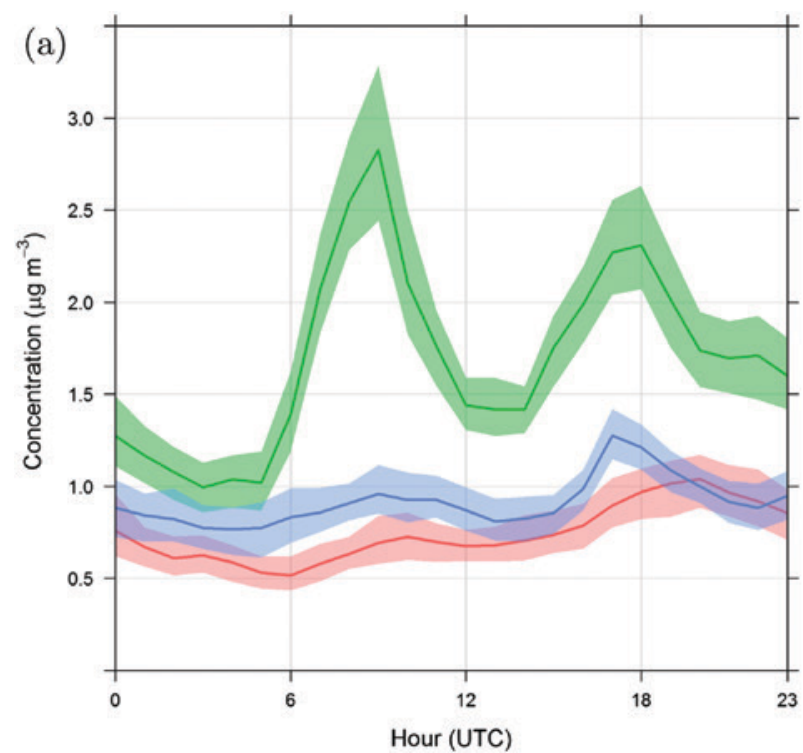

time (BST)], but it remains open if the remaining hour difference is caused by a change in the emissions or the earlier growth of the mixed layer suppressing the peak at the receptor site.

In an effort to understand other components of the particulate burden, Fig. 15a shows the hourly median diurnal cycles of selected nonrefractory $\mathrm{PM}_{1}$ chemical species (nitrate, sulfate, and organics) measured with four AMS (Canagaratna et al. 2007) at NK and MR, and for the winter IOP also for Harwell and Detling. The average chemical composition during the campaigns is shown in Fig. 15b, which also includes nonrefractory chloride and ammonium. The mean nonrefractory $\mathrm{BC}$ in $\mathrm{PM}_{1}$ in Detling of approximately $0.7 \mu \mathrm{g} \mathrm{m}^{-3}$ is relatively high and peaks in the evening, consistent with residential wood burning. Sulfate shows no strong pattern with time of day or with time of year nor does it show an urban increment, as the highest wintertime concentrations were measured at the rural site at Harwell. This is consistent with previous results that show that sulfate is produced on regional scales and does not show an appreciable urban increment (Abdalmogith and Harrison 2006).

In contrast, during the day the particulate matter organic mass loadings are significantly enhanced at the roadside site (MR) compared with the urban background site (NK). The average increment is larger in winter than in summer, because of a significant accumulation in the street canyon during some inversion situations. Organics are also higher

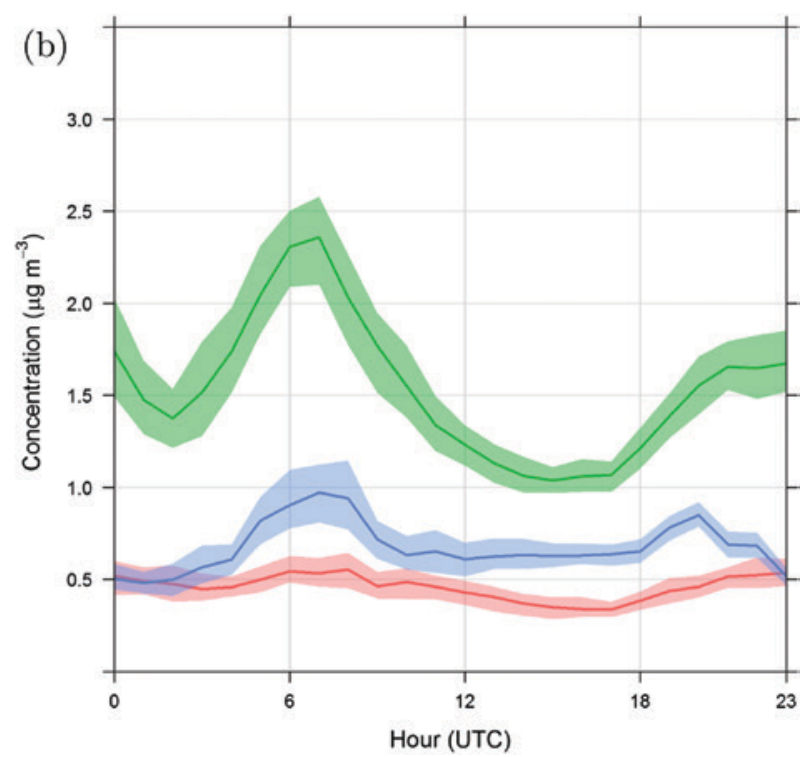

FIG. 14. Mean diurnal cycle of BC concentrations measured with an aethalometer for Harwell (red), Detling (blue), and NK (green), with the shaded areas indicating the $95 \%$ confidence intervals for (a) winter IOP and (b) summer IOP. 
at NK than at Detling (Fig. 15a), indicating an urban increment in PM pollution that is consistent with the urban increment in $\mathrm{CO}$ concentration shown in Fig. 7. Harwell, which was often downwind of the London conurbation during the winter IOP, was subject to similar concentrations of organic aerosol as NK. Organics are incremented by London due to the sources of primary aerosols and VOCs (see the "VOCs in London" section). The organics have a complex profile, with a peak in the morning corresponding to the rush hour and an additional peak at night. The wintertime organics at NK show a larger increase at night than at Detling, likely due to a combination of increased emissions from cooking and space heating, reduced $\mathrm{MH}$, and condensation of semivolatile secondary organic matter. Summertime organics at NK (Fig. 15b) also show a distinct peak at night.

As a consequence of its semivolatile nature, particulate matter nitrate concentrations are highest at night and in the winter, when temperatures are lowest. This is similar to findings in other regions such as central Europe (Lanz et al. 2010). During the winter IOP, average nitrate concentrations were similar across the sites (Fig. 15b), confirming that most of the nitrate was regional. At the more urban-impacted sites, the diurnal cycle shows a more pronounced morning peak, owing to increased $\mathrm{NO}_{x}$ emissions within the city during the morning rush hour caused by anthropogenic emissions of precursors and oxidants combined with lower temperature that favors condensation of nitrate. $\mathrm{NO}_{x}$ can be converted to nitrate through the oxidation of $\mathrm{NO}_{2}$ by $\mathrm{OH}$ during the day or by the hydrolysis of $\mathrm{N}_{2} \mathrm{O}_{5}$ during the night. The nitrate peaks slightly later at Detling than at the other sites, possibly due to higher levels of oxidants in the urban environment that increase the rate of formation and condensation. Summertime nitrate mass loadings at $\mathrm{NK}$ are lower compared to winter and show close agreement between the two urban sites, again reaching the highest concentrations at night. Nonrefractory chloride mass loadings in $\mathrm{PM}_{1}$ are typically much less than $0.5 \mu \mathrm{g} \mathrm{m}^{-3}$ and relatively constant throughout the day, and are larger in winter

Fig. 15. (a) Hourly median diurnal cycle for nonrefractory PM, total organics (green), nitrate (blue), and sulfate (red) measured with an aerosol mass spectrometer during the (left) winter IOP and (right) summer IOP and (b) aerosol nonrefractory component concentrations during both IOPs. The mean BC mass during winter IOP at Detling was about $0.7 \mu \mathrm{g} \mathrm{m}^{-3}$ with a standard deviation of $0.13 \mu \mathrm{g} \mathrm{m}^{-3}$. than in summer. The measured ammonium mass loading is equal to the amount needed to neutralize the sulfate, nitrate, and chloride in the particles at all sites.

As described in "The ClearfLo measurement campaigns" section, health risks are associated with the composition and size distribution of PM (Oberdörster et al. 2002, 2004). Particle number concentrations are influenced by many factors, such as regional
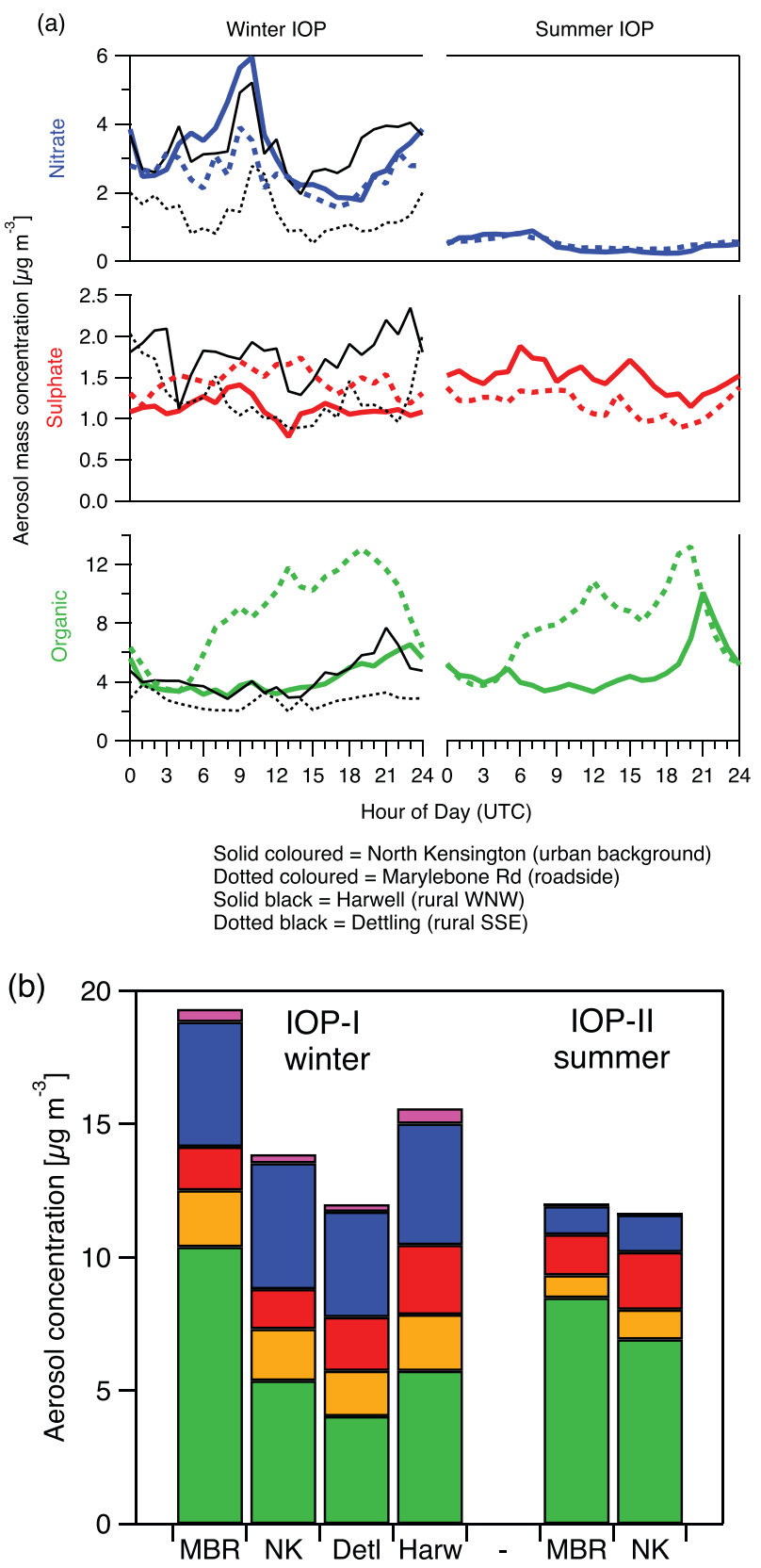


\section{FAAM AIRCRAFT MEASUREMENTS DURING CLEARFLO}

synergistic aircraft campaign by the U.K. Facility for AAirborne Atmospheric Measurements (FAAM) took place during the ClearfLo summer IOP. This consisted of five approximately 5 -h-long flights between 1100 and 1600 UTC around London (Fig. SB2) in late July and early August 2012. In situ and remotely sensed measurements of $\mathrm{CO}_{2}, \mathrm{H}_{2} \mathrm{O}, \mathrm{CH}_{4}, \mathrm{~N}_{2} \mathrm{O}, \mathrm{O}_{3}, \mathrm{CO}$, $\mathrm{HNO}_{3}, \mathrm{HCN}$, aerosol, thermodynamics, and many other tracers were recorded throughout the planetary boundary layer and free troposphere [between $30 \mathrm{~m}$ and $10 \mathrm{~km}$; see Allen et al. (2014) for further information]. Repeated sampling upwind and downwind of London characterized the London plume for a series of case studies, which enables the calculation of regional spatially resolved fluxes of greenhouse gases (O'Shea et al. 2014). Figure SB3 shows an example of measurements upwind and downwind of London on FAAM flight B725 on 9 August 2012, characterized by well-mixed Atlantic westerly maritime inflow. The urban increment over the background in this example (around 50 ppbv for both $\mathrm{CH}_{4}$ and $\mathrm{CO}$ ), when analyzed

FIG. SB2. FAAM flights B724 (thick track) and B725 (thin track) on $30 \mathrm{Jul}$ and 9 Aug 20I2, respectively, color scaled for altitude as indicated in the legend. Permission is granted by TerraMetrics Inc. to display the map underlain here.

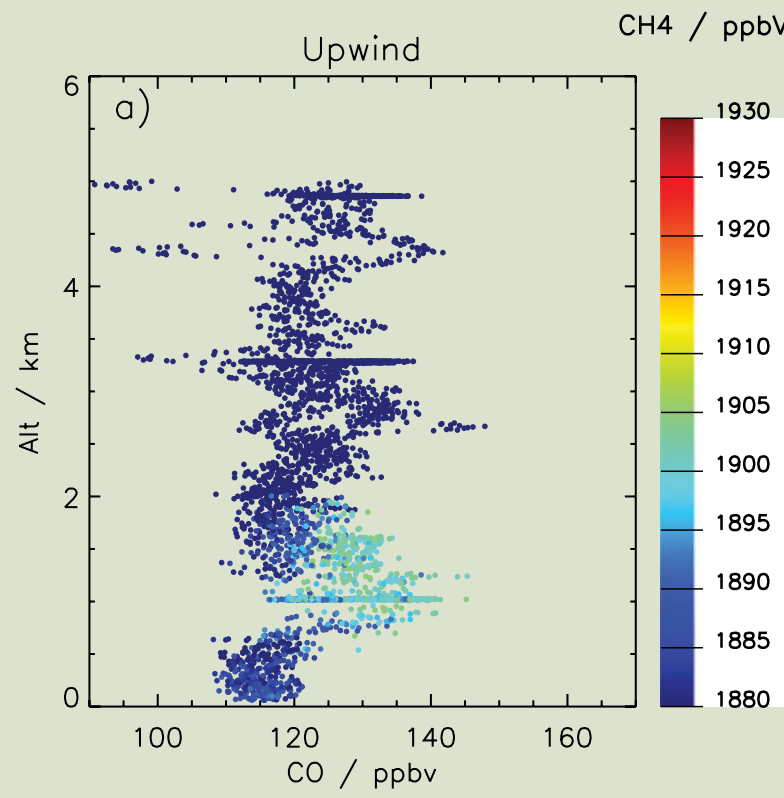

alongside measured winds and interpreted using both Lagrangian and dispersive transport models such as the Hybrid Single-Particle Lagrangian Integrated Trajectory model (HYSPLIT) and NAME, respectively, permits the calculation of surface fluxes from London with quantifiable uncertainties. This represents an important validation dataset for bottom-up-derived national emissions inventories and regional (and urban) air quality models.
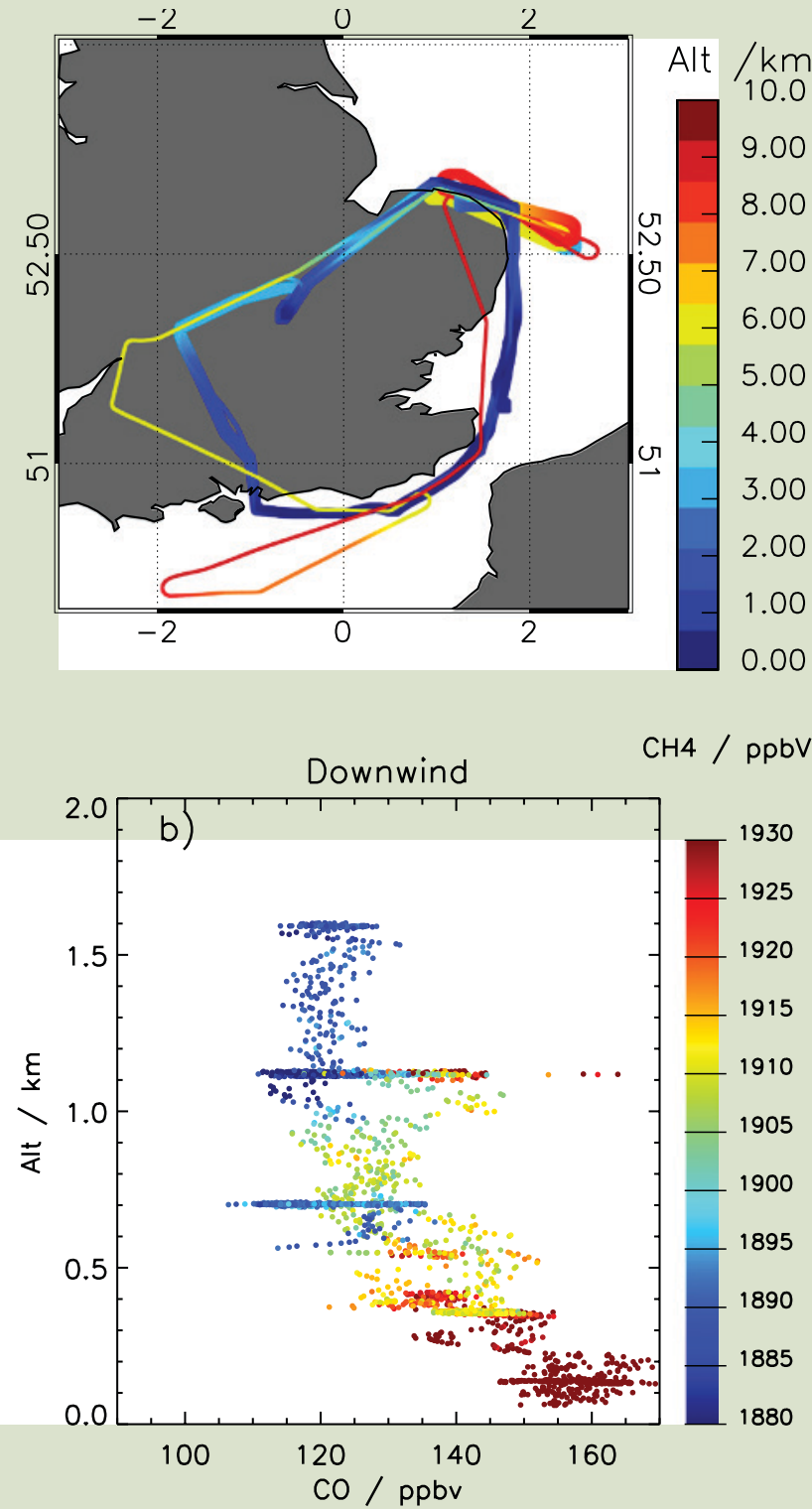

FIG. SB3. Vertical profiles of methane and CO concentration on FAAM flight B725: (a) upwind and (b) downwind of London. Methane is color scaled as per legend.

advection, local generation, dispersion, atmospheric processing, temperature, and volatility. Figure 16 shows the particle number size distribution between
14 and $600 \mathrm{~nm}$ at MR, NK, and Harwell. Number size concentrations are a factor of 4 higher near traffic than in the urban background and a factor 

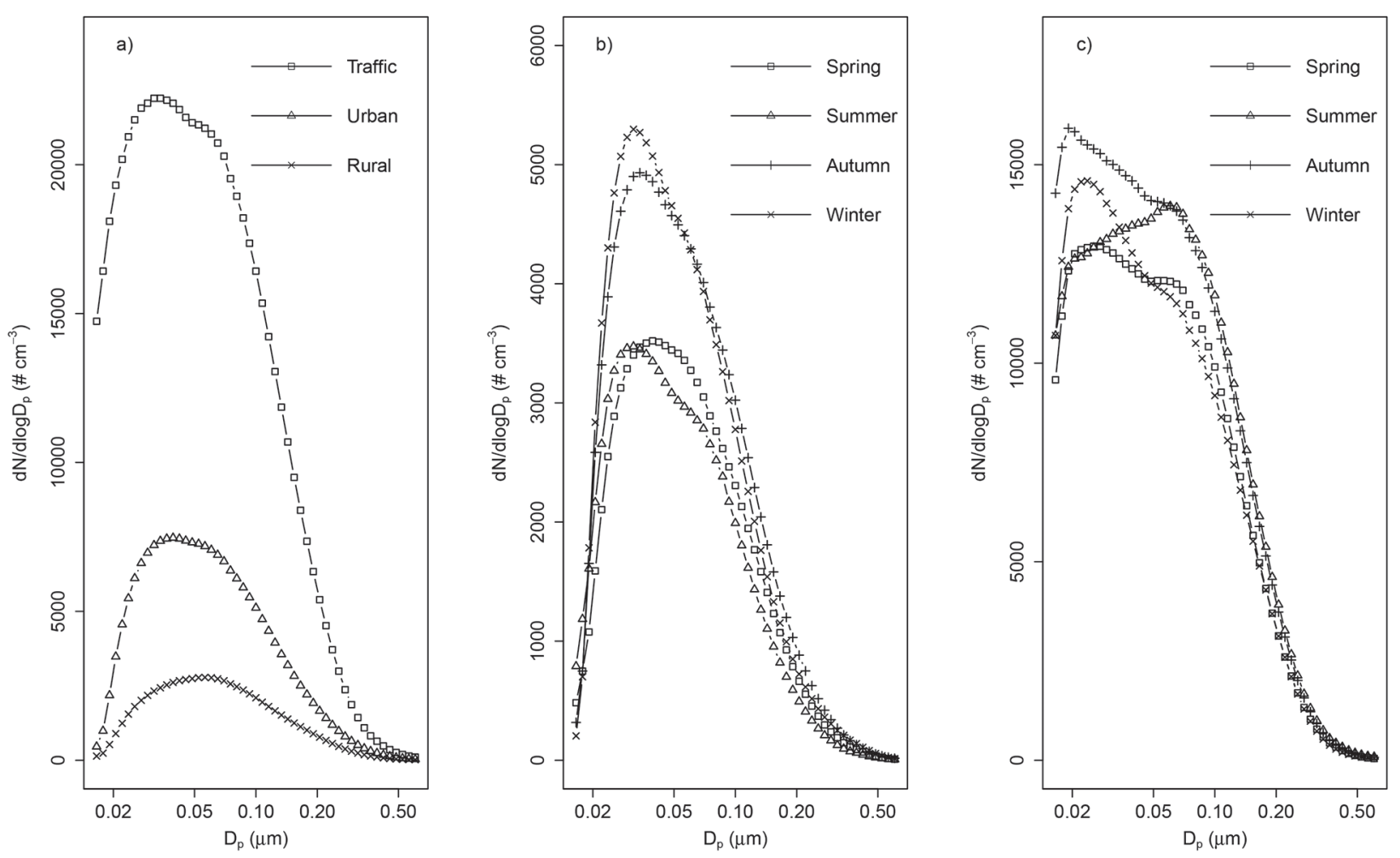

FIG. 16. Particle number size distribution by site for (a) MR (traffic), NK (urban background), and Harwell (rural), and by time of year for (b) the urban increment (NK-Harwell) and (c) the traffic increment (NK-MR). Note the different $y$-axis scales.

of 10 higher than in the rural background. These site and seasonal differences are associated with the seasonal changes to emissions, advection of regional pollutants into the urban background, but also the dilution effect of MH. The smaller (less than $100 \mathrm{~nm}$ ) particle mode in the traffic increment is more evident in autumn and winter (Fig. 16b), while in summer the larger mode is more dominant, consistent with the volatile tendencies of the nucleation mode from road traffic (Dall'Osto et al. 2011). The urban increment is largest in autumn and winter, especially for smaller particles (Fig. 16b). A likely explanation is the lower temperature, since more nanoparticles are formed in the exhaust at lower temperature (e.g., Bukowiecki et al. 2003), and they are less liable to evaporation (Dall'Osto et al. 2011). The reasons for the seasonal differences in the traffic increment are manifold and will be the subject of further analysis. From a meteorological perspective, the lower $\mathrm{MH}$ in winter traps particles in a smaller volume, and in the early morning hours in winter, when the rush hour starts before the boundary layer growth, dispersion is likely to be less effective.

CONCLUSIONS. ClearfLo's interdisciplinary approach brought together detailed measurements of meteorology, gas-phase chemistry, and particulate loading in and around London over a period of 2 years. Two IOP campaigns made more detailed measurements in the urban and rural background, and provide a dataset to analyze winter and summer concentrations of key pollutants and their precursors in London. This comprehensive, rich dataset provides the opportunity to explore the interactions between meteorology, gasphase chemistry, and particulates and to evaluate air quality and weather forecast models.

This paper, the first synthesis paper for ClearfLo, provides not only some important new results but demonstrates that future analyses from ClearfLo will inform our understanding of the influence of the diurnal evolution of the urban boundary layer and levels of radical species and VOCs upon air pollutant concentrations in London. The vertical distribution of turbulence measurements enables us to extend the measurements of the vertical turbulent structure of the urban boundary layer below the lowest Doppler lidar gate and to explain the influence of turbulent mixing on measured concentrations. The sensible heat flux varies strongly with urban land use, vertical elevation, and season, and it was successfully related to the evolution of the mixing height observed. The elevated turbulence measurements demonstrate 
the presence of decoupling events associated with a weakly stable residual layer at the top of BT Tower during the early morning hours in summer and during nighttime in winter. These events are relevant from an air quality perspective when pollutants released at street level are mixed over a very small volume, leading to only little dilution. These processes need to be captured by air quality models. The corresponding diurnal cycles of the main gas-phase pollutants and PM show the impact of the changes in mixing properties with season and the impact of traffic sources and additional pathways for $\mathrm{O}_{3}$ formation, which are favored in the urban environment. Analysis of the photochemical reactivity of London's boundary layer determines the fraction of $\mathrm{O}_{3}$ that is produced locally in London in summer, and total $\mathrm{OH}$ reactivity is found to be as high as $100 \mathrm{~s}^{-1}$. An apportionment of $\mathrm{PM}_{1}$ for London and the corresponding variability in aerosol mass with location, time of day, and season is shown. Such analyses are needed to formulate legislation around sources and processes controlling the urban increment and contribution of regional sources to PM.

The results demonstrate that the observational strategy provides us with the data needed to quantify the urban increment, and the horizontal and vertical variability of concentrations in London. The IOPs described briefly in this paper will allow the oxidation budget of the urban environment to be constrained and the extensive testing of current (plus new) chemical transport models.

ACKNOWLEDGMENTS. ClearfLo is funded by NERC under Grant NE/H00324X/1 (lead proposal) and is coordinated by NCAS. Grant references for split awards are NE/ H003169/1, NE/H003150/1, NE/H003177/1, NE/H003207/1, NE/H003185/1, NE/H003223/1, NE/H00324X/1, NE/ H003193/1, NE/H003231/1, and NE/H003142/1. Funding for the FAAM aircraft was provided by NERC Grant Reference NE/I021276/1. We thank the flight operations team and aircrew from NERC Airborne Research and Survey Facility for providing access to the Dornier 228 aircraft and for providing support to Project: GB12/09. Thanks go to the Chelsea and Kensington council, which granted us access to the Trellick, Dartrey, and Grenfell towers (Adrian Bowman and Kyri Eleftheriou-Vaus, Royal Borough Kensington and Chelsea). Thanks also go to Islington Borough. Thanks go to BT for supporting instrument deployment on BT Tower (Bob Semon, Wayne Loeber, Andy Beale, and Eric Anderson). We thank Steve Neville of Westminster City Council for permission to use its building as a measurement site. Thanks to John Lally for technical support throughout, and to Barbara
Brooks and James Groves for technical support during the intensive observation periods. We thank the Sion Manning School and the adjacent community center. We thank Dr. Paul Smith and Lukas Pauscher for putting in the BLS, LAS, and ceilometers and communications infrastructure on the towers. We thank Roger Moore and his staff at the Kent Showground, Detling, for help with installing and operating the Detling winter IOP site. We acknowledge the participation of the following in the winter IOP measurements at Detling: John Jayne, Andrew Freedman, William Brooks, Jonathan Franklin, Paola Massoli, Edward Fortner, Puneet Chhabra, Mark Zahnizer, Harald Stark, and Douglas Worsnop (Aerodyne Research, Inc.); W. Berk Knighton (Montana State University); Kyle Gorkowski (Los Alamos National Laboratory, United States); and Timothy Martin and Richard Coulter (Argonne National Laboratory, United States). Funding for the Kent Showground deployment was provided in part by U.S. Department of Energy, Award DE-SC0006002. Thanks to the British Atmospheric Data Centre (BADC) for hosting our data. We acknowledge funding from the SNF (Grant 200021_132467/1) and the European Community's Seventh Framework Programme (FP7/2007-2013, Grant 312284). Thanks to the Met Office for use of the NAME model and for providing AQUM simulations and forecast data from the UKV, in particular Lucy Davis, Paul Agnew, and Humphrey Lean. We thank Carl Percival (University of Manchester) and Christine Braban (Centre for Ecology and Hydrology). We thank Philip Naysmith and Gordon Cook (SUERC) for undertaking carbon-14 analyses on samples from North Kensington. The methodology for conducting air quality and meteorology predictions with the WRFCMAQ modeling system by the University of Hertfordshire was partly based on that developed in CREMO (project funded by the Environment Agency), MEGAPOLI (FP7 project), and TRANSPHORM (FP7 project). We thank Noel Clancy and Trevor Ingham (University of Leeds) for the technical assistance. The aerosol measurements received additional support through NERC through the MC4 project (Grant Reference NE/H008136/1) and the Department of Environment, Food and Rural Affairs (Defra). We thank the Royal Geographical Society with IBG for housing a ceilometer. We thank Alex Bjorkegren, Grace Healey, William Morrison, John Mustchin, and Lukas Pauscher (King's College London), who fixed the equipment operated by KCL Geography and with numerous other students checked things 365 days a year for the entire ClearfLo period.

\section{REFERENCES}

Abdalmogith, S. S., and R. M. Harrison, 2006: An analysis of spatial and temporal properties of daily 
sulphate, nitrate and chloride concentrations at UK urban and rural sites. J. Environ. Monit., 8, 691-699, doi:10.1039/b601562j.

Allan, J. D., and Coauthors, 2009: Contributions from transport, solid fuel burning and cooking to primary organic aerosols in two UK cities. Atmos. Chem. Phys., 9, $19103-19$ 157, doi:10.5194 lacpd-9-19103-2009.

Allen, G., and Coauthors, 2014: Atmospheric composition and thermodynamic retrievals from the ARIES airborne TIR-FTS system-Part 2: Validation and results from aircraft campaigns. Atmos. Meas. Tech. Discuss., 7, 3397-3441, doi:10.5194/amtd-7-3397-2014.

Allwine, K. J., and J. E. Flaherty, 2006: Joint Urban 2003: Study overview and instrument locations. Pacific Northwest National Laboratory Rep. PNNL15967, 92 pp. [Available online at www.pnl.gov/main /publications/external/technical_reports/PNNL -15967.pdf.]

—, M. J. Leach, L. W. Stockham, J. S. Shinn, R. P. Hosker, J. F. Bowers, and J. C. Pace, 2004: Overview of Joint Urban 2003-An atmospheric dispersion study in Oklahoma City. Symp. on Planning, Nowcasting, and Forecasting in the Urban Zone/Eighth Symp. on Integrated Observing and Assimilation Systems for Atmosphere, Oceans, and Land Surface, Seattle, WA, Amer. Meteor. Soc., J7.1. [Available online at https://ams.confex.com/ams/84Annual/techprogram /paper_74349.htm.]

Appel, K. W., C. Chemel, S. J. Roselle, X. V. Francis, R.-M. Hu, R. S. Sokhi, S. T. Rao, and S. Galmarini, 2012: Examination of the Community Multiscale Air Quality (CMAQ) model performance over the North American and European domains. Atmos. Environ., 53, 142-155, doi:10.1016/j.atmosenv .2011.11.016.

Arnold, S., and Coauthors, 2004: Introduction to the DAPPLE Air Pollution Project. Sci. Total Environ., 332, 139-153, doi:10.1016/j.scitotenv.2004.04.020.

Barlow, J. F., T. M. Dunbar, E. G. Nemitz, C. R. Wood, M. W. Gallagher, F. Davies, E. O'Connor, and R. M. Harrison, 2011: Boundary layer dynamics over London, UK, as observed using Doppler lidar during REPARTEE-II. Atmos. Chem. Phys., 11, 2111-2125, doi:10.5194/acp-11-2111-2011.

_- C. H. Halios, S. E. Lane, and C. R. Wood, 2015: Observations of urban boundary layer structure during a strong urban heat island event. Environ. Fluid Mech., 15, 373-398, doi:10.1007 /s10652-014-9335-6.

Barrett, A. I., R. J. Hogan, and E. J. O'Connor, 2009: Evaluating forecasts of the evolution of the cloudy boundary layer using diurnal composites of radar and lidar observations. Geophys. Res. Lett., 36, L17811, doi:10.1029/2009GL038919.

Belcher, S. E., 2005: Mixing and transport in urban areas. Philos. Trans. Roy. Soc. London, A363, 29472968, doi:10.1098/rsta.2005.1673.

Bell, M. K., J. M. Sanet, and F. Dominici, 2004: Timeseries studies of particulate matter. Annu. Rev. Public Health, 25, 247-280, doi:10.1146/annurev .publhealth.25.102802.124329.

Bigi, A., and R. M. Harrison, 2010: Analysis of the air pollution climate at a central urban background site. Atmos. Environ., 44, 2004-2012, doi:10.1016/j .atmosenv.2010.02.028.

Bohnenstengel, S. I., S. Evans, P. A. Clark, and S. E. Belcher, 2011: Simulations of the London urban heat island. Quart. J. Roy. Meteor. Soc., 137, 1625-1640, doi:10.1002/qj.855.

—, I. Hamilton, M. Davies, and S. E. Belcher, 2013: Impact of anthropogenic heat emissions on London's temperatures. Quart. J. Roy. Meteor. Soc., 140, 687-698, doi:10.1002/qj.2144.

Bond, T. C., and Coauthors, 2013: Bounding the role of black carbon in the climate system: A scientific assessment. J. Geophys. Res. Atmos., 118, 5380-5552, doi:10.1002/jgrd.5017.

Brunekreef, B., and S. T. Holgate, 2002: Air pollution and health. Lancet, 360, 1233-1242, doi:10.1016 /S0140-6736(02)11274-8.

Bukowiecki, N., J. Dommen, A. S. H. Prevot, E. Weingartner, and U. Baltensperger, 2003: Fine and ultrafine particles in the Zürich (Switzerland) area measured with a mobile laboratory: An assessment of the seasonal and regional variation throughout a year. Atmos. Chem. Phys., 3, 1477-1494, doi:10.5194 lacp-3-1477-2003.

Canagaratna, M. R., and Coauthors, 2007: Chemical and microphysical characterization of ambient aerosols with the aerodyne aerosol mass spectrometer. Mass Spectrom. Rev., 26, 185-222, doi:10.1002/mas 20115 .

Carslaw, D. C., S. D. Beevers, J. E. Tate, E. Westmoreland, and M. L. Williams, 2011: Recent evidence concerning higher NO $x$ emissions from passenger cars and light duty vehicles. Atmos. Environ., 45, 7053-7063, doi:10.1016/j.atmosenv.2011.09.063.

Chemel, C., and R. S. Sokhi, 2012: The response of London's urban heat island to a marine air intrusion in an easterly wind regime. Bound.-Layer Meteor., 144, 65-81, doi:10.1007/s10546-012-9705-x.

— , and Coauthors, 2010: Evaluation of a CMAQ simulation at high resolution over the UK for the calendar year 2003. Atmos. Environ., 44, 2927-2939, doi:10.1016/j.atmosenv.2010.03.029. 
Clapp, L. J., and M. E. Jenkin, 2001: Analysis of the relationship between ambient levels of $\mathrm{O}_{3}, \mathrm{NO}_{2}$ and $\mathrm{NO}$ as a function of $\mathrm{NO}_{x}$ in the UK. Atmos. Environ., 35, 6391-6405, doi:10.1016/S1352-2310(01)00378-8. COMEAP, 2010: The mortality effects of longterm exposure to particulate air pollution in the United Kingdom: A report by the Committee on the medical effects of air pollutants. Health Protection Agency for COMEAP, Public Health England, 108 pp. [Available online at www.gov .uk/government/uploads/system/uploads /attachment_data/file/304641/COMEAP_mortality _effects_of_long_term_exposure.pdf.]

Cros, B. P., and Coauthors, 2004: The ESCOMPTE program: An overview. Atmos. Res., 69, 241-279, doi:10.1016/j.atmosres.2003.05.001.

Dall'Osto, M., A. Thorpe, D. C. S. Beddows, R. M. Harrison, J. F. Barlow, T. Dunbar, P. I. Williams, and H. Coe, 2011: Remarkable dynamics of nanoparticles in the urban atmosphere. Atmos. Chem. Phys., 11, 6623-6637, doi:10.5194/acp-11-6623-2011.

Grimmond, C. S. B., and T. R. Oke, 1999: Aerodynamic properties of urban areas derived from analysis of surface form. J. Appl. Meteor., 38, 1262-1292, doi:10.1175/1520-0450(1999)0382.0.CO;2.

— , and Coauthors, 2010: The International Urban Energy Balance Models Comparison Project: First results from phase 1. J. Appl. Meteor. Climatol., 49, 1268-1292, doi:10.1175/2010JAMC2354.1.

Guerreiro, C., F. de Leeuw, and V. Foltescu, 2013: Air quality in Europe-2013 report. European Environment Agency Rep. 9/2013, 112 pp., doi:10.2800 192843.

Hacker, J. N., S. E. Belcher, and R. K. Connell, 2005: Beating the heat: Keeping UK buildings cool in a warmer climate. UK Climate Impacts Programme Briefing Rep., 32 pp. [Available online at www .ukcip.org.uk/wordpress/wp-content/PDFs/Beating _heat.pdf.]

Harman, I. N., and S. E. Belcher, 2006: The surface energy balance and boundary-layer over urban street canyons. Quart. J. Roy. Meteor. Soc., 132, 2749-2768, doi:10.1256/qj.05.185.

Harrison, R. M., and Coauthors, 2012: Atmospheric chemistry and physics in the atmosphere of a developed megacity (London): An overview of the REPARTEE experiment and its conclusions. Atmos. Phys. Chem., 12, 3065-3114, doi:10.5194 lacp-12-3065-2012.

Heal, M. R., 2014: The application of carbon-14 to the source apportionment of atmospheric carbonaceous particulate matter: A review. Anal. Bioanal. Chem., 406, 81-98, doi:10.1007/s00216-013-7404-1.
Hogan, R. J., A. L. M. Grant, A. J. Illingworth, G. N. Pearson, and E. J. O'Connor, 2009: Vertical velocity variance and skewness in clear and cloud-topped boundary layers as revealed by Doppler lidar. Quart. J. Roy. Meteor. Soc., 135, 635-643, doi:10.1002/qj.413.

Hunt, J. C., Y. V. Timoshkina, S. I. Bohnenstengel, and S. E. Belcher, 2013: Implications of climate change for expanding cities worldwide. Proc. Inst. Civ. Eng.: Urban Des. Plann., 166, 241-254, doi:10.1680/udap.10.00062.

Illingworth, A. J., and Coauthors, 2007: Cloudnet: Continuous evaluation of cloud profiles in seven operational models using ground-based observations. Bull. Amer. Meteor. Soc., 88, 883-898, doi:10.1175 /BAMS-88-6-883.

Janssen, N. A., J. Schwartz, A. Zanobetti, and H. H. Suh, 2002: Air conditioning and source-specific particles as modifiers of the effect of $\mathrm{PM}(10)$ on hospital admissions for heart and lung disease. Environ. Health Perspect., 110, 43-49.

Jenkin, M. E., S. M. Saunders, and M. J. Pilling, 1997: The tropospheric degradation of volatile organic compounds: A protocol for mechanism development. Atmos. Environ., 31, 81-104, doi:10.1016 /S1352-2310(96)00105-7.

Jerrett, M., and Coauthors, 2009: Long-term ozone exposure and mortality. N. Engl. J. Med., 360, 1085-1095, doi:10.1056/NEJMoa0803894.

Johnson, H., R. S. Kovats, G. R. McGregor, J. Stedman, M. Gibbs, H. Walton, L. Cook, and E. Black, 2005: Impact of the 2003 heat wave on mortality and hospital admissions. Engl. Health Stat. Quart., 25, 6-11.

Jones, A. R., D. J. Thomson, M. Hort, and B. Devenish, 2007: The U.K. Met Office's next-generation atmospheric dispersion model, NAME III. Air Pollution Modeling and Its Application XVII, C. Borrego and A-L. Norman, Eds., Springer, 580-589.

Kotthaus, S., and C. S. B. Grimmond, 2012: Identification of micro-scale anthropogenic $\mathrm{CO}_{2}$, heat and moisture sources-Processing eddy covariance fluxes for a dense urban environment. Atmos. Environ., 57, 301-316, doi:10.1016/j .atmosenv.2012.04.024.

$\longrightarrow$, and _ 2014a: Energy exchange in a dense urban environment-Part I: Temporal variability of longterm observations in central London. Urban Climate, 10, 261-280, doi:10.1016/j.uclim.2013.10.002.

_ and _ - 2014b, Energy exchange in a dense urban environment-Part II: Impact of spatial heterogeneity of the surface. Urban Climate, 10, 281-307, doi:10.1016/j.uclim.2013.10.001.

Langford, B., and Coauthors, 2010: Fluxes and concentrations of volatile organic compounds above central 
London, UK. Atmos. Chem. Phys., 10, 627-645, doi:10.5194/acp-10-627-2010.

Lanz, V. A., and Coauthors, 2010: Characterization of aerosol chemical composition with aerosol mass spectrometry in Central Europe: An overview. Atmos. Chem. Phys., 10, 10453-10 471, doi:10.5194 /acp-10-10453-2010.

Liu, D., and Coauthors, 2011: Carbonaceous aerosols contributed by traffic and solid fuel burning at a polluted rural site in northwestern England. Atmos. Chem. Phys., 11, 1603-1619, doi:10.5194 /acp-11-1603-2011.

Loridan, T., F. Lindberg, O. Jorba, S. Kotthaus, S. Grossman-Clarke, and C. S. B. Grimmond, 2013: High resolution simulation of surface heat flux variability across central London with urban zones for energy partitioning. Bound.-Layer Meteor., 147, 493-523, doi:10.1007/s10546-013-9797-y.

Masson, V., and Coauthors, 2008: The Canopy and Aerosol Particles Interactions in TOulouse Urban Layer (CAPITOUL) experiment. Meteor. Atmos. Phys., 102, 135-157, doi:10.1007/s00703-008-0289-4.

Mavrogianni, M., and Coauthors, 2011: The comfort, energy and health implications of London's urban heat island. Build. Serv. Eng. Res. Technol., 32, 35-52, doi:10.1177/0143624410394530.

Mohr, C., and Coauthors, 2013: Contribution of nitrated phenols to wood burning brown carbon light absorption in Detling, United Kingdom during winter time. Environ. Sci. Technol., 47, 6316-6324, doi:10.1021 /es400683v.

Mustchin, J., L. Pauscher, H. C. Ward, S. Kotthaus, M. Gouvea, and C. S. B. Grimmond, cited 2013: Comparison of three large aperture scintillometer models over London. [Available online at www.geo .uni-tuebingen.de/arbeitsgruppen/angewandte -geowissenschaften/forschungsbereich/umweltphysik /scintillometer-workshop-2013/programme.html.]

Oberdörster, G., Z. Sharp, V. Atudorei, A. Elder, R. Gelein, A. Lunts, W. Kreyling, and C. Cox, 2002: Extrapulmonary translocation of ultrafine carbon particles following whole-body inhalation exposure of rats. J. Toxicol. Environ. Health, A65, 1531-1543, doi:10.1080/00984100290071658.

,,,,----- W. Kreyling, and C. Cox, 2004: Translocation of inhaled ultrafine particles to the brain. Inhalation Toxicol., 16, 437-445, doi:10.1080/08958370490439597.

O'Shea, S. J., and Coauthors, 2014: Area fluxes of carbon dioxide, methane and carbon monoxide derived from airborne measurements around Greater London: A case study during summer 2012. J. Geophys. Res. Atmos., 119, 4940-4952, doi:10.1002/2013JD021269.
Platt, U., and J. Stutz, 2008: Differential Optical Absorption Spectroscopy: Principles and Applications. Physics of Earth and Space Environments, Springer-Verlag, 598 pp.

Pope, R. J., N. H. Savage, M. P. Chipperfield, S. R. Arnold, and T. J. Osborn, 2014: The influence of synoptic weather regimes on UK air quality: Analysis of satellite column $\mathrm{NO}_{2}$. Atmos. Sci. Lett., 5, 211-217, doi:10.1002/asl2.492.

Rotach, M. W., and Coauthors, 2005: BUBBLEAn urban boundary layer meteorology project. Theor. Appl. Climatol., 81, 231-261, doi:10.1007 /s00704-004-0117-9.

Rydin, Y., and Coauthors, 2012: Shaping cities for health: Complexity and the planning of urban environments in the 21st century. Lancet, 379, 2079-2108, doi:10.1016/S0140-6736(12)60435-8.

Schwarz, J. P., and Coauthors, 2010: The detection efficiency of the single particle soot photometer. Aerosol Sci. Technol., 44, 612-628, doi:10.1080/02786826 .2010.481298.

Shah, A. S. V., J. P. Langrish, H. Nair, D. A. McAllister, A. L. Hunter, K. Donaldson, D. E. Newby, and N. L. Mills, 2013: Global association of air pollution and heart failure: A systematic review and meta-analysis. Lancet, 382, 1039-1048, doi:10.1016 /S0140-6736(13)60898-3.

Singh, V., R. S. Sokhi, and J. Kukkonen, 2013: $\mathrm{PM}_{2.5}$ concentrations in London for 2008-A modeling analysis of contributions from road traffic. J. Air Waste Manage. Assoc., 64, 509-518, doi:10.1080 /10962247.2013.848244.

Stedman, J. R., 2004: The predicted number of air pollution related deaths in the UK during the August 2003 heatwave. Atmos. Environ., 38, 1087-1090, doi:10.1016/j.atmosenv.2003.11.011.

Stone, D., L. K. Whalley, and D. E. Heard, 2012: Tropospheric $\mathrm{OH}$ and $\mathrm{HO}_{2}$ radicals: Field measurements and model comparisons. Chem. Soc. Rev., 41, 6348-6404, doi:10.1039/c2cs35140d.

Turpin, B. J., and J. J. Huntzicker, 1995: Identification of secondary organic aerosol episodes and quantification of primary and secondary organic aerosol concentrations during SCAQS. Atmos. Environ., 29, 3527-3544, doi:10.1016/1352-2310(94)00276-Q.

UN Department of Economic and Social Affairs, cited 2013: On-line data: Urban and rural population; Population in urban and rural areas. [Available online at http://esa.un.org/unpd/wup/unup/index_panel1 .html.]

Valach, A. C., B. Langford, E. Nemitz, A. R. MacKenzie, and C. N. Hewitt, 2014: Concentrations of selected volatile organic compounds at kerbside and 
background sites in central London. Atmos. Environ., 95, 456-467, doi:10.1016/j.atmosenv.2014.06.052.

von Schneidemesser, E., and P. S. Monks, 2013: Air qual-

ity and climate-Synergies and trade-offs. Environ.

Sci.: Processes Impacts, 15, 1315-1325, doi:10.1039 /c3em00178d.

— - _ , and C. Plass-Duelmer, 2010: Global comparison of VOC and $\mathrm{CO}$ observations in urban areas. Atmos. Environ., 44, 5053-5064, doi:10.1016/j .atmosenv.2010.09.010.

_ _ _ _ V. Gros, J. Gauduin, and O. Sanchez, 2011: How important is biogenic isoprene in an urban environment? A study in London and Paris. Geophys. Res. Lett., 38, L19804, doi:10.1029/2011GL048647.

Ward, H. C., J. G. Evans, and C. S. B. Grimmond, 2013: Multi-season eddy covariance observations of energy, water and carbon fluxes over a suburban area in Swindon, UK. Atmos. Chem. Phys., 13, 4645-4666, doi:10.5194/acp-13-4645-2013.

Whalley, L. K., M. A. Blitz, M. Desservettaz, P. W. Seakins, and D. E. Heard, 2013: Reporting the sensitivity of Laser Induced Fluorescence instruments used for
$\mathrm{HO}_{2}$ detection to an interference from $\mathrm{RO}_{2}$ radicals and introducing a novel approach that enables $\mathrm{HO}_{2}$ and certain $\mathrm{RO}_{2}$ types to be selectively measured. Atmos. Meas. Tech. Discuss., 6, 6249-6292, doi:10.5194 /amtd-6-6249-2013.

WHO, 2006: Air Quality Guidelines: Global Update 2005; Particulate Matter, Ozone, Nitrogen Dioxide and Sulfur Dioxide. WHO, 484 pp.

_ - 2013: Review of evidence on health aspects of air pollution-REVIHAAP project: Final technical report. World Health Organization Regional Office for Europe Tech. Rep., 302 pp. [Available online at www.euro.who .int/_data/assets/pdf_file/0004/193108/REVIHAAP -Final-technical-report-final-version.pdf?ua=1.]

Wood, C. R., and Coauthors, 2009: Dispersion experiments in central London: The 2007 DAPPLE project. Bull. Amer. Meteor. Soc., 90, 955-970, doi:10.1175/2009BAMS2638.1.

—- and Coauthors, 2010: Turbulent flow at $190 \mathrm{~m}$ height above London during 2006-2008: A climatology and the applicability of similarity theory. Bound.-Layer Meteor., 137, 77-96, doi:10.1007/s10546-010-9516-x.

\section{CLIMATE CHANGE/POLICY}

"This book is timely because global climate change policy is a mess....

Drawing on concrete examples and a broad range of social science theory, this book convincingly makes the case for a social learning approach to both adaptation and emissions mitigation."

- Steve Rayner, James Martin Professor of Science and Civilization, University of Oxford

\section{Adaptive Governance and Climate Change}

RONALD D. BRUNNER AND AMANDA H. LYNCH

As greenhouse gas emissions and temperatures at the poles continue to rise, so do damages from extreme weather events affecting countless lives. Meanwhile, ambitious international efforts to cut emissions have proved to be politically ineffective or infeasible. There is hope, however, in adaptive governance-an approach that has succeeded in some communities and can be undertaken by others around the globe.

In this book:

- A political and historical analysis of climate change policy

- How adaptive governance works on the ground

- Why local, bottom-up approaches should complement global-scale negotiations

(ㄷ) 2010, PAPERBACK, 424 PAGES ISBN: 978-1-878220-97-4 AMS CODE: AGCC LIST \$35 MEMBER \$22 